Dom. Cien., ISSN: 2477-8818

Vol. 4, núm.4., oct, 2018, pp. 308-360

DOI: $10.23857 /$ dc.v4i4.842

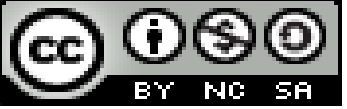

Ciencias de la salud

Artículo de investigación

\title{
Tratamiento cardiovascular en pacientes con hipercolesterolemia
}

\section{Cardiovascular treatment in patients with hypercholesterolemia}

\section{Tratamento cardiovascular em pacientes com hipercolesterolemia}

\author{
José F. Calderón-Ponce ${ }^{\mathrm{I}}$ \\ jose.calderon.p@gmail.com \\ Liliana P. Cepeda-García II \\ liliana-cepe@hotmail.com \\ Franklin J. Anchundia-Delgado III \\ frankanchun@hotmail.com
}

\author{
Cindy G. Mera-Holguín IV \\ cindy,meraa@hotmail.com \\ César D. Pibaque-Tigua V \\ cesar.pibaque@gmail.com \\ José E. Anchundia-Baque VI \\ jose.anchun1@hotmail.com
}

Recibido: 07 de septiembre de 2018 * Corregido: 28 de septiembre de 2018 * Aceptado: 25 de octubre de 2018

\footnotetext{
I. Médico General, Distrito 13D03, Jipijapa, Ecuador.

II. Médico Residente del Hospital Jipijapa, Jipijapa, Ecuador.

III. Médico Residente del Hospital Jipijapa, Jipijapa, Ecuador.

IV. Médico Cirujano, Analista Zonal de Habilitación, Certificación y Acreditación ACESS, Quito, Ecuador.

V. Médico Residente del Hospital Jipijapa, Jipijapa, Ecuador.

VI. Médico Cirujano; Residente Hospital Jipijapa, Jipijapa, Ecuador.
} 


\section{Resumen}

Objetivo: Valorar la adecuación en la prescripción de hipolipemiantes y conocer diversas características clinicoepidemiológicas de los pacientes con hipercolesterolemia. Método: Población objeto de estudio: todos los pacientes con hipercolesterolemia pertenecientes a tres centros de salud urbanos. Muestreo por conglomerados monoetápico $(\mathrm{n}=724)$. Estudio descriptivo con dos tipos de diseño: longitudinal retrospectivo y transversal. Para el primero de los diseños se utilizaron las nuevas tablas de riesgo cardiovascular (RCV) de Sheffield; para el segundo, las de Framingham por categorías (Grundy). Resultados: Entre los pacientes en prevención primaria, hubo una adecuación en la prescripción en un $44,2 \%$ de los pacientes. Tienen actualmente un riesgo absoluto elevado $(\geq$ $20 \%$ a 10 años) un $8,9 \%(1,1)$ de nuestros pacientes de 30 a 74 años de edad en prevención primaria. Están con un riesgo relativo elevado un $6,0 \%(0,8)$ y levemente por encima del límite un $18,1 \%$ $(2,0)$. Conclusiones: En más de la mitad de los pacientes se prescribieron hipolipemiantes sin estar indicados mediante una tabla de riesgo. El RCV actual de nuestros pacientes es satisfactorio.

Palabras claves: Hipercolesterolemia. Riesgo cardiovascular. Prevención primaria. Atención primaria. 


\section{Abstract}

Objective: To assess the appropriateness of lipid-lowering treatment and to determine the clinical and epidemiological characteristics of patients with hypercholesterolemia. Method: The study population comprised all the patients diagnosed with hypercholesterolemia in three urban health centres. A sample of 724 patients was obtaind through a one-stage conglomerate method. A descriptive study was performed with two types of designs: retrospective and longitudinal, and cross-sectional. For the first we used the new Sheffield tables for cardiovascular risk; for the second, the Framingham categorical tables (Grundy). Results: Among patients in primary prevention, prescription of lipid-lowering therapy was appropiate in $44.2 \%$. A total of $8.9 \%(\mathrm{SE}=1.1)$ of the patients aged $30-74$ years in primary prevention had a high absolute risk ( $\geq 20 \%$ over 10 years). Six percent (0.8) had a high relativd risk and 18.1\% (2.0) had a moderately above-average risk. Conclusions: More than the half of the patients were prescribed lipid-lowering treatment that was not indicated by risk tables. The current cardiovascular risk of our patients is satisfactory.

Key words: Hypercholesterolemia. Cardiovascular risk. Primary prevention. Primary care. 


\section{Introducción.}

La enfermedad cardiovascular, al igual que en el resto de los países occidentales, es la primera causa de muerte en España (37,8\% de todas las defunciones en el trienio 1995-1997). En los últimos años se ha producido un descenso de las tasas ajustadas de mortalidad, pero el número de muertes por cardiopatía isquémica está aumentando debido, fundamentalmente, al envejecimiento de la población. Sin embargo, de forma comparativa, España presenta una mortalidad coronaria más baja que la mayoría de los países occidentales.

La enfermedad cardiovascular es de origen multifactorial, y la hipercolesterolemia debe ser considerada en el contexto de otros factores de riesgo; de ahí la importancia de evaluar el riesgo cardiovascular global. El riesgo coronario y/o cardiovascular (RCV) es la probabilidad de presentar una enfermedad coronaria o cardiovascular en un período de tiempo determinado, generalmente 5 o 10 años. Existen dos métodos de cálculo del RCV: cualitativos y cuantitativos. Estos últimos emplean las llamadas tablas de riesgo cardiovascular, de las que las más utilizadas son las basadas en la ecuación de riesgo del estudio de Framingham.

Una vez estimado el RCV y conocida la eficacia de la intervención, en la práctica asistencial hay que tomar la decisión terapéutica basada, sobre todo, en el conocimiento de si el RCV es lo suficientemente elevado como para obtener un beneficio con el tratamiento.

Esta adecuación de la prescripción, en este caso de hipolipemiantes, es uno de los objetivos del presente trabajo (objetivo 1). El otro es conocer diversas características clinicoepidemiológicas actuales de nuestros pacientes con hipercolesterolemia (objetivo 2).

\footnotetext{
311 Vol. 4, núm. 4, octubre 2018, pp. 308-360 José F. Calderón-Ponce; Liliana P. Cepeda-García; Franklin J. Anchundia-Delgado; Cindy G. MeraHolguín; César D. Pibaque-Tigua; José E. Anchundia-Baque
} 


\section{Pacientes y método}

La población objeto de estudio correspondió a todos los pacientes con diagnóstico de hipercolesterolemia pertenecientes a tres centros de salud urbanos ubicados en Santiago de Compostela. El total de médicos de familia adscritos a estos centros es de 27.

El muestreo fue por conglomerados monoetápico. Las unidades de primera etapa (UPE) se corresponden con los cupos médicos. El tamaño muestral, teniendo en cuenta un muestreo simple aleatorio (MSA), para una confiabilidad del 95\%, una p del 50\% y una precisión deseada del 5\%, sería de 384. Si el muestreo es por conglomerados, como en nuestro caso, para alcanzar el grado de precisión prefijado es necesario seleccionar una muestra de tamaño mayor que la que demanda el MSA. Para esto habría que multiplicar el tamaño calculado $(n=384)$ por un número deff comprendido entre 1,5 y 3. Multiplicando por 1,5 obtendríamos un número aproximado de 600 pacientes. Para conseguir una muestra de dicho tamaño precisamos elegir 8 conglomerados (por la suma de las UPE que menos pacientes con diagnóstico de hipercolesterolemia tienen). El procedimiento para elegir esos 8 conglomerados fue aleatorio. La muestra final estuvo integrada por todas las unidades de análisis (pacientes con diagnóstico de hipercolesterolemia) en esas 8 UPE $(\mathrm{n}=$ 724). Este método es equiprobabilístico, siendo la probabilidad de inclusión de cada UPE (y de cada unidad de análisis) de 0,296.

En el presente estudio descriptivo se trabajó con dos tipos de diseño: para el primero de los objetivos antes mencionados con un diseño longitudinal retrospectivo, y para el segundo con uno transversal.

\footnotetext{
312 Vol. 4, núm. 4, octubre 2018, pp. 308-360 José F. Calderón-Ponce; Liliana P. Cepeda-García; Franklin J. Anchundia-Delgado; Cindy G. MeraHolguín; César D. Pibaque-Tigua; José E. Anchundia-Baque
} 
Los pacientes fueron clasificados como hipercolesterolémicos sobre la base del Programa del Adulto del Área Sanitaria:

a) Pacientes en prevención primaria: dos analíticas con colesterol total $\geq 250 \mathrm{mg} / \mathrm{dl}$. Si el colesterol total está entre 200 y $250 \mathrm{mg} / \mathrm{dl}$, se debe valorar el cLDL, siendo diagnóstico si cLDL 130-160 mg/dl y dos o más factores de riesgo (FR) o cLDL $\geq 160 \mathrm{mg} / \mathrm{dL}$ sin FR.

b) Pacientes en prevención secundaria: cLDL > $130 \mathrm{mg} / \mathrm{dl}$.

Se usó la historia clínica como fuente de información. Para el diseño retrospectivo (objetivo 1) se recogieron las variables del momento del diagnóstico y la instauración del tratamiento farmacológico o de controles posteriores al diagnóstico (caso de no estar tratados farmacológicamente). Aparte de la fecha de nacimiento y el género, en el momento del diagnóstico se recogieron las variables siguientes: fecha del diagnóstico, antecedentes familiares de enfermedad cardiovascular prematura, concentraciones de colesterol total, cLDL y cHDL, hábito tabáquico, hipertensión arterial, diabetes, hipertrofia ventricular izquierda (HVI) y tipo de prevención (primaria o secundaria). Estas mismas variables se volvieron a recoger en el momento de la instauración del tratamiento farmacológico, junto con la estatina y/o fibrato prescrito.

Para el diseño transversal (objetivo 2) se recogieron esas mismas variables pertenecientes al último control (y en caso de estar actualizado). El trabajo de campo fue realizado en marzo de 2001.

Toda esta información fue recogida por cada médico en su respectivo cupo, al tener éste un mayor conocimiento de sus propios pacientes. Para evitar el sesgo de información en la clasificación de cada paciente en la adecuación de la prescripción, se suprimió de la base de datos informática

\footnotetext{
313 Vol. 4, núm. 4, octubre 2018, pp. 308-360 José F. Calderón-Ponce; Liliana P. Cepeda-García; Franklin J. Anchundia-Delgado; Cindy G. MeraHolguín; César D. Pibaque-Tigua; José E. Anchundia-Baque
} 
cualquier identificación sobre el cupo médico; asimismo, la interpretación de la adecuación (objetivo 1) la realizó la persona encargada del procesamiento de los datos.

Dicha interpretación se hizo mediante las nuevas tablas de Sheffield, siendo el objetivo de éstas detectar qué pacientes se pueden beneficiar de tratamiento farmacológico.

Estas tablas indican puntos de corte (ratio colesterol total/cHDL) equivalentes a un RCV de 15 y de un $30 \%$ a los 10 años.

Para el diseño transversal (objetivo 2) también fue ajeno al médico el cálculo del RCV actual. Dicho cálculo fue realizado mediante las tablas de Framingham por categorías. Las variables que utiliza son: edad (limitada de 30 a 74 años), género, tabaquismo, diabetes y las categorías de cHDL, colesterol total y presión arterial (PA) sistólica y diastólica. Con la modificación de Grundy ${ }^{13}$ se puede realizar el cálculo del riesgo absoluto (RA) de presentar hard CHD o «episodios duros» (angina inestable, IAM y muerte coronaria). Además, podemos calcular el riesgo relativo (RR), que es el cociente entre el RA y el riesgo bajo (o el riesgo medio de una población). Definición de riesgo bajo: persona de la misma edad, PA $<120 / 80 \mathrm{mmHg}$, colesterol total 160-199 $\mathrm{mg} / \mathrm{dl}$, cHDL $>45 \mathrm{mg} / \mathrm{dl}$, no fumadora y no diabética.

La aplicación estadística utilizada para el procesamiento de los datos fue el módulo de Epi Info conocido como CSAMPLE (Cluster Sampling Analysis), por dar las estimaciones pertinentes de un muestreo por conglomerados.

Para el análisis factorial se utilizaron índices estadísticos descriptivos para variables cualitativas e cuantitativas, tipo proporción y media, junto con su correspondiente error estándar (EE). Para el análisis bifactorial fueron utilizadas pruebas de asociación entre dos variables 
cualitativas (procedimiento Tables de CSAMPLE) y entre una cualitativa y otra cuantitativa (procedimiento Means). Como salida normal de resultados en las tablas 2 x 2, el programa CSAMPLE da el valor puntual de la odds ratio (OR), mejor denominada aquí razón de prevalencias, y risk difference $(\mathrm{RD})$, que sería la diferencia de prevalencias entre las dos categorías de la variable antecedente, junto con sus correspondientes intervalos de confianza (IC)

\section{Resultados.}

De los 724 pacientes seleccionados, un 57,5\% (EE, 2,7) son mujeres.

\section{Diseño longitudinal retrospectivo}

La edad media al diagnóstico fue de 56,3 (1,3) años. Las concentraciones medias de colesterol total, cLDL y cHDL fueron respectivamente, de $274,8(3,2), 189,3(3,0)$ y $53,7(0,9)$ mg/dl. La media de tiempo entre el diagnóstico y el inicio de tratamiento farmacológico fue de 4,1 $(0,2)$ meses.

Entre los pacientes en prevención primaria, hubo una inadecuación en la prescripción (según las tablas de Sheffield para un riesgo del $30 \%$ a los 10 años) en un 55,8\% de los pacientes (tabla 1 ). 


\begin{tabular}{lccrrr}
\hline \multicolumn{3}{c}{ Tabla 1. Adecuación de la prescripción según la tabla } \\
de Sheffield \\
\hline Indicación de tratarniento & \multicolumn{2}{c}{ RCV del } & $15 \%$ & \multicolumn{2}{c}{ RCV del $30 \%$} \\
según la tabla & $\%$ & EE & $\%$ & EE \\
\hline No y paciente no toma & 31,7 & 3,7 & 37,1 & 4,8 \\
SI y paciente toma & 26,0 & 1,7 & 7,1 & 1,2 \\
No y paciente toma & 33,6 & 4,7 & 53,8 & 4,7 \\
S y y paciente no torra & 8,7 & 1,8 & 2,0 & 0,7 \\
\hline
\end{tabular}

Diseño transversal

La media de edad actual de los pacientes es de 61,4 (0,9) años. Están en prevención primaria un $89,2 \%(2,1)$. La prevalencia de otros factores de riesgo en nuestros pacientes con hipercolesterolemia fue: tabaquismo en un $13,8 \%(2,1)$, HTA en un $44,6 \%(3,2)$ y diabetes en un $18,9 \%(1,9)$.

Las concentraciones medias de colesterol total, cLDL y cHDL son significativamente inferiores en los pacientes en prevención secundaria (tabla 2). Entre los de prevención primaria, aquellos con tratamiento farmacológico tienen menores concentraciones de colesterol total y cLDL (tabla 3). 


\begin{tabular}{|c|c|c|c|}
\hline & $\begin{array}{l}\text { Prevención } \\
\text { primaria }\end{array}$ & $\begin{array}{l}\text { Prevención } \\
\text { secundaria }\end{array}$ & Total \\
\hline Colesterol total & $\begin{array}{c}240,4(3,1) \\
\text { Dif. } 25,3\end{array}$ & $\begin{array}{c}215,1(4,9) \\
\text { IC del } 95 \% \text {, dif. } 11,8-38,6\end{array}$ & $237,3(2,8)$ \\
\hline CLDL & $\begin{array}{c}164,3(3,7) \\
\text { Dif. } 22,9\end{array}$ & $\begin{array}{c}141,4(3,2) \\
\text { IC del } 95 \% \text {, dif. } 11,1-34,7\end{array}$ & $161,8(3,3)$ \\
\hline CHDL & $\begin{array}{c}54,9(1,1) \\
\text { Dif. } 5,1\end{array}$ & $\begin{array}{c}49,8(1,6) \\
\text { IC del } 95 \%, \text { dif. } 1,3-8,8\end{array}$ & $54,3(0,9)$ \\
\hline
\end{tabular}

Tabla 3. Concentraciones medias de CT, LDL y HDL (en $\mathrm{mg} / \mathrm{dl}$ ) según tratamiento farmacológico o no (sólo prevención primaria)

\begin{tabular}{lcc}
\hline & No tratados & Tratados \\
\hline Colesterol total & $248,0(2,8)$ & $234,3(4,3)$ \\
& Dif. 13,7 & IC del $95 \%$, dif. $4,5-23,0$ \\
CLDL & $172,6(2,9)$ & $158,5(4,6)$ \\
& Dif. 14,1 & IC del $95 \%$, dif. $5,4-22,8$ \\
CHDL & $54,4(1,5)$ & $55,3(1,2)$ \\
& IC del $95 \%$, dif. $-3,7-1,9(\mathrm{NS})$ & \\
\hline
\end{tabular}

Recibe tratamiento farmacológico (estatinas en un 96\% de los casos) un 60,8\% $(5,0)$ de los pacientes; entre los pacientes en prevención primaria, dicho porcentaje es del $58,1 \%(5,8)$. Las estatinas más prescritas son: atorvastatina (37,5\%), simvastatina (23\%), lovastatina (15\%) y cerivastatina $(14,3 \%)$. 
Tiene un RA elevado ( $\geq 20 \%$ a 10 años) un $8,9 \%(1,1)$ de nuestros pacientes de 30 a 74 años en prevención primaria (fig. 1). Está con un RR elevado un $6,0 \%(0,8)$ y está levemente por encima del límite del riesgo un $18,1 \%(2,0)$.

\section{Figura 1}

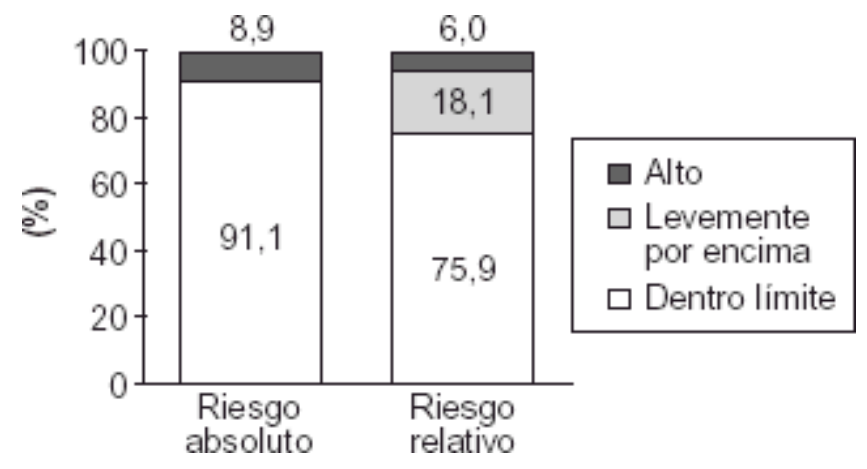

El RA elevado está presente en un 1,4\% entre las mujeres, frente a un 19\% entre los varones $(\mathrm{OR}=16,4 ; \mathrm{IC}$ del 95\%, 6,7-40,2); si analizamos el RR elevado, la relación es del 2,1 frente a $11,4 \%(\mathrm{OR}=6,0 ; \mathrm{IC}$ del 95\%, 3-12).

\section{Discusión.}

En principio puede llamar la atención del lector que el tipo de muestreo fuese por conglomerados, ya que normalmente proporciona menor precisión que un MSA. La razón fundamental se deriva de otra utilidad práctica del estudio: facilitar listados exhaustivos de pacientes con riesgos elevados para ser hipotéticamente susceptibles de una actuación más oportuna de cara a reducir su RCV. Hay que tener presente que en las historias clínicas de los médicos del área existe

\footnotetext{
\begin{tabular}{l|l}
318 & Vol. 4, núm. 4, octubre 2018, pp. 308-360 \\
José F. Calderón-Ponce; Liliana P. Cepeda-García; Franklin J. Anchundia-Delgado; Cindy G. Mera-
\end{tabular} Holguín; César D. Pibaque-Tigua; José E. Anchundia-Baque
} 
un registro casi nulo de la cuantificación del RCV y nada en absoluto sobre valores de riesgo relativo.

A la conocida limitación de tablas y gráficos derivados de Framingham, cuando se aplican a una población con una incidencia de enfermedad coronaria muy inferior a la americana (como es el caso de la española) ${ }^{14}$, podríamos decir que aun así sigue siendo preferible utilizar cualquiera de las tablas de riesgo que ninguna ${ }^{9}$; además, ello no es óbice para un posible y deseable uso en un futuro próximo de unas tablas de riesgo adaptadas a la población española.

Los aspectos más novedosos del presente trabajo se centran, por un lado, en el uso de las nuevas tablas de Sheffield ${ }^{11} \mathrm{y}$, por otro, en las valoraciones del riesgo relativo mediante las tablas de Framingham por categorías de Grundy ${ }^{13}$.

Respecto a las primeras, ahora tienen en cuenta el cociente colesterol total/cHDL, de mayor validez en la medición del $\mathrm{RCV}^{15,16}$ y un mejor predictor de enfermedad coronaria. Justificamos su elección, en el objetivo de la adecuación de la prescripción, porque identifica claramente a los pacientes que se pueden beneficiar o no de tratamiento farmacológico.

Para el segundo de los objetivos interesaba más la cuantificación del RCV. Por ello, utilizamos la variante de Grundy de «episodios duros» dado que no sobrestiman tanto el riesgo de nuestra población ${ }^{9}$, además de posibilitarnos el cálculo del RR. Por tales motivos discrepamos ligeramente de las recomendaciones del Programa de Actividades Preventivas y de Promoción de la Salud (PAPPS), en la Guía de prevención cardiovascular ${ }^{17}$ de 1996, en el sentido de seguir utilizando la tabla de Framingham clásica; creemos que es bueno aprovecharse de las modificaciones introducidas en los últimos años. 
En los resultados se confirma la sospecha que tienen muchos profesionales acerca de la excesiva prescripción de fármacos hipolipemiantes (fundamentalmente estatinas); así, en más de la mitad de nuestros pacientes $(53,8 \%)$ se prescribió tratamiento farmacológico sin estar indicado por la tabla de Sheffield (tomando el umbral de riesgo del 30\%). En otro estudio ${ }^{18}$, realizado en el Reino Unido, se obtuvo un $37,9 \%$ de decisiones inapropiadas, aunque en nuestro estudio, ent re los pacientes que requieren tratamiento farmacológico hubo un menor porcentaje de decisiones inapropiadas $(21,8$ frente a $35,1 \%)$; por otra parte, entre los pacientes que no requieren fármacos, nuestras decisiones inapropiadas fueron mayores (59,2 frente a 40,1\%). Otros estudios de ámbito español $^{19,20}$, aunque también con metodología diferente de la nuestra, señalaban que sólo un 37,5 y un $32 \%$ de los pacientes cumplían los criterios de calidad de tratamiento farmacológico.

Nos gustaría romper una lanza en favor de la tabla de Sheffield y señalarla como la más estricta en la recomendación de terapia farmacológica. Así, en diferentes estudios ${ }^{21,22}$, donde se compararon distintos algoritmos para determinar la necesidad de tratamiento farmacológico en pacientes sin enfermedad cardiovascular, el de Sheffield fue el que recomendó menor número de tratamientos. Sin embargo, un estudio escocés ${ }^{23}$ realizado con médicos de familia y enfermería indica una menor preferencia de uso por las tablas de Sheffield en relación con las de Nueva Zelanda o las de las Sociedades Británicas. Ello puede ser comprensible por el carácter numérico de las primeras en contraste con el carácter gráfico de las dos restantes. De todas formas, creemos que tampoco supone tanto inconveniente tener una calculadora sencilla en la consulta para obtener el cociente colesterol total/cHDL.

\footnotetext{
320 Vol. 4, núm. 4, octubre 2018, pp. 308-360 José F. Calderón-Ponce; Liliana P. Cepeda-García; Franklin J. Anchundia-Delgado; Cindy G. MeraHolguín; César D. Pibaque-Tigua; José E. Anchundia-Baque
} 
Asimismo, en relación con otros autores ${ }^{19}$ que mencionan un intervalo medio de 18 meses, sorprende el corto espacio de tiempo entre el diagnóstico y el inicio del tratamiento farmacológico en nuestros pacientes (4,1 meses).

Centrándonos ahora en el diseño transversal (objetivo 2), debemos empezar corroborando una similar distribución por género y media de edad de nuestros pacientes con relación a otros estudios de ámbito español ${ }^{19}$. También coincidimos en la distribución según el tipo de prevención en la que se encuentran los pacientes (primaria, 89\%; secundaria, 11\%) ${ }^{10,19}$. Sin embargo, la prevalencia de otros factores de riesgo cambia en el sentido de contar nosotros con más diabéticos (18,9 frente a $13,9-14,7 \%)$ pero con menos fumadores $(13,8$ frente a $22,8-34,5 \%)$.

Las concentraciones medias de colesterol total, cLDL y cHDL obtenidas son significativamente inferiores en los pacientes en prevención secundaria, en los que se habla de rebajar el cLDL por debajo de $125 \mathrm{mg} / \mathrm{dl}$, e idealmente llegar a menos de $100 \mathrm{mg} / \mathrm{dl}^{14}$; sin embargo, en nuestros pacientes los valores medios de cLDL alcanzaron $141 \mathrm{mg} / \mathrm{dl}$, cifra coincidente con el estudio PREVESE ${ }^{24}$, aunque realmente distante del objetivo ideal. Este valor medio se produce a pesar de que, en su gran mayoría (un 84\%), nuestros pacientes hipercolesterolémicos en prevención secundaria son tratados farmacológicamente. Este porcentaje es algo superior al trabajo de Bonet et $\mathrm{al}^{19}$, que fue de un 71,4\%. En el estudio PREVESE ${ }^{24}$ era tratado con hipolipemiantes tan sólo un $6,7 \%$, aunque hay que tener en cuenta que en dicho estudio estaban contemplados todos los pacientes en prevención secundaria y no sólo los de hipercolesterolemia como FR.

También sorprenden los valores medios de colesterol total y de cLDL en los pacientes en prevención primaria que reciben hipolipemiantes $(234$ y $158 \mathrm{mg} / \mathrm{dl}$, respectivamente). Estos valores medios se producen a pesar de que la mitad de las estatinas prescritas fueron atorvastatina y

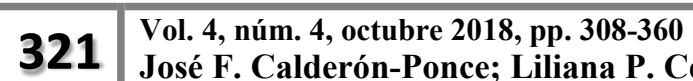
José F. Calderón-Ponce; Liliana P. Cepeda-García; Franklin J. Anchundia-Delgado; Cindy G. MeraHolguín; César D. Pibaque-Tigua; José E. Anchundia-Baque
} 
cerivastatina, de mayor poder hipolipemiante ${ }^{25}$. Es importante recordar la suspensión de la comercialización de la cerivastatina en agosto de 2001, con posterioridad a la recogida de información para este estudio.

Ya mencionamos anteriormente que, de entre las tablas de Framingham, es preferible la utilización de la puntuación de riesgo de «episodios duros», dado que no sobrestiman tanto el riesgo de nuestra población. De esta forma se obtuvo que casi un 9 y un $6 \%$ de nuestros pacientes tienen, respectivamente, RA elevados y RR elevados, lo cual interpretamos como indicadores óptimos de control de nuestros pacientes con hipercolesterolemia. Dado que otros estudios trabajan con las tablas originales de Framingham, las comparaciones no serían rigurosas; aún así, sorprende la diferencia entre nuestro valor y el encontrado por Bonné et al ${ }^{10}(32,5 \%)$. A esta diferencia también puede estar contribuyendo en una magnitud importante el hecho de que en este último estudio la valoración del riesgo se haya realizado al inicio del período de seguimiento.

Creemos que podría ser muy interesante una mayor difusión de las tablas de RCV, entre los médicos y el personal de enfermería del área, y un adiestramiento práctico de su uso mediante talleres de corta duración, realizados en los propios centros de salud. Con esto ganaríamos en valoración del RCV más completa de nuestros pacientes y en coste-efectividad del tratamiento con fármacos hipolipemian tes.

\section{La Hipercolesterolemia Familiar (HF)}

Es una enfermedad hereditaria que se expresa desde el nacimiento, y que cursa con un aumento en las concentraciones plasmáticas de colesterol, principalmente del colesterol transportado por las lipoproteínas de baja densidad (c-LDL).

\footnotetext{
322 Vol. 4, núm. 4, octubre 2018, pp. 308-360 
Es un trastorno muy frecuente y se estima que al menos 1 de cada 250 personas en la población general presenta HF. En España, se calculan en unas 190.000 las personas con HF.

La importancia de su diagnóstico precoz radica en el elevado riesgo de presentar un Infarto de Miocardio (IM) u otra enfermedad ateroesclerótica vascular en edades tempranas de la vida. La enfermedad cardiovascular se manifiesta en más del 50\% de los pacientes con HF antes de los 55 años de edad.

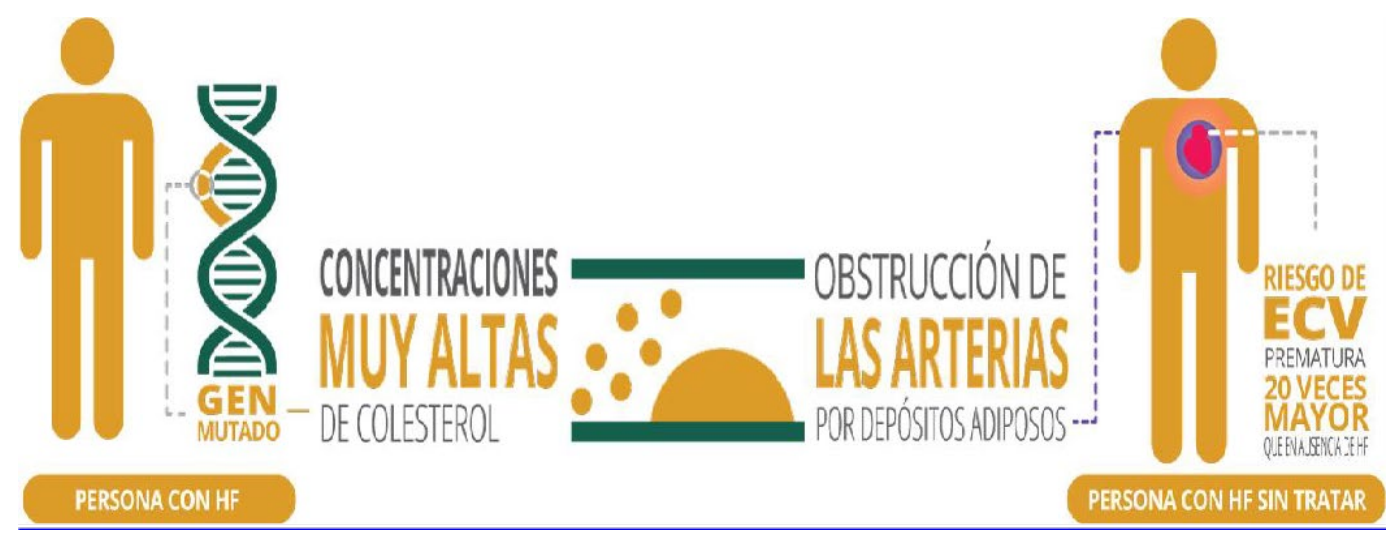

¿Qué causa la HF y como se hereda?

El defecto principal se produce por una mutación en el gen que codifica el receptor de las LDL (rLDL), que son los encargados de eliminar el colesterol de la sangre a nivel hepático. Al disponer de una menor cantidad de receptores, ya sea parcial o total, el colesterol LDL aumenta considerablemente en la sangre, favoreciendo su depósito en las arterias y el desarrollo de una placa que puede estrechar la luz de las arterias, lo que produce la ateroesclerosis. 
La alta concentración de colesterol

"malo" es un factor de riesgo

determinante para la ateroesclerosis

(formación de placas de ateroma en

la capa interna de la pared arterial)

que puede provocar una

enfermedad cardiovascular

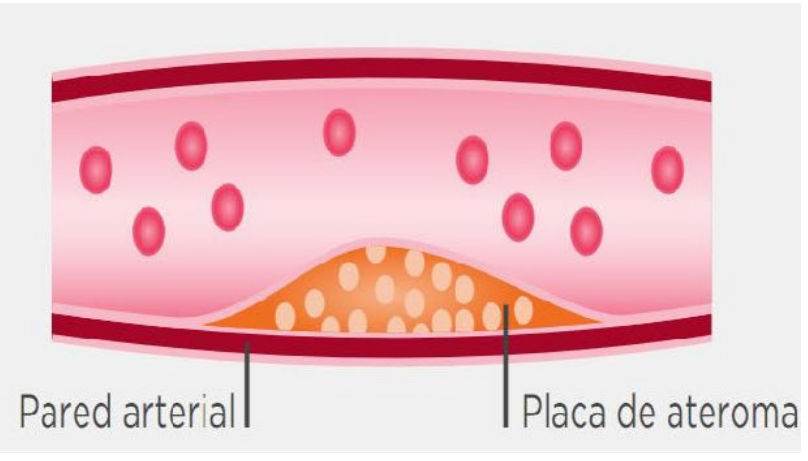

Por su mecanismo de transmisión, se reconocen dos variantes:

- Heterocigota: uno de los alelos tiene una mutación en el gen y el otro es normal. En este caso, el paciente tiene el $50 \%$ de la dotación de receptores-LDL normofuncionantes, y el resto están ausentes (mutaciones de alelo nulo) o no funcionan adecuadamente (mutaciones de alelo defectuoso).

- Homocigota: ambos alelos están defectuosos (el del padre y la madre), lo que produce una ausencia prácticamente total de receptores LDL.

\section{EXISTEN DOS VARIANTES DE HF:}
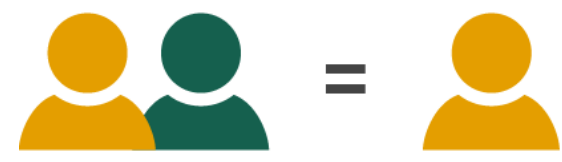

HF heterocigota (HFHe) -

HF heredada de uno de los progenitores
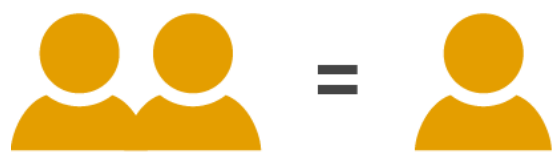

HF homocigota (HFHo) -

HF heredada de ambos progenitores

Afecto $\square$ No afecto 
Una persona afecta de $\mathrm{HF}$, tiene el $50 \%$ de probabilidades de transmitir el gen anormal a sus descendientes, hijos e hijas, y un 50\% de traspasar la información genética correcta. Por lo tanto, aproximadamente la mitad de los miembros de una familia heredarán la HF. Si un niño o adulto, hijo de un paciente con HF, tiene niveles normales de colesterol, es muy probable que haya heredado el gen normal, y por tanto no desarrollará la enfermedad ni la transmitirá a su descendencia. Algunos estudios han demostrado que puede existir hasta un $8 \%$ de personas portadoras de una mutación con niveles normales de colesterol. En este caso pueden transmitir el gen defectuoso a su descendencia. Por eso, es muy importante la realización del diagnóstico genético.

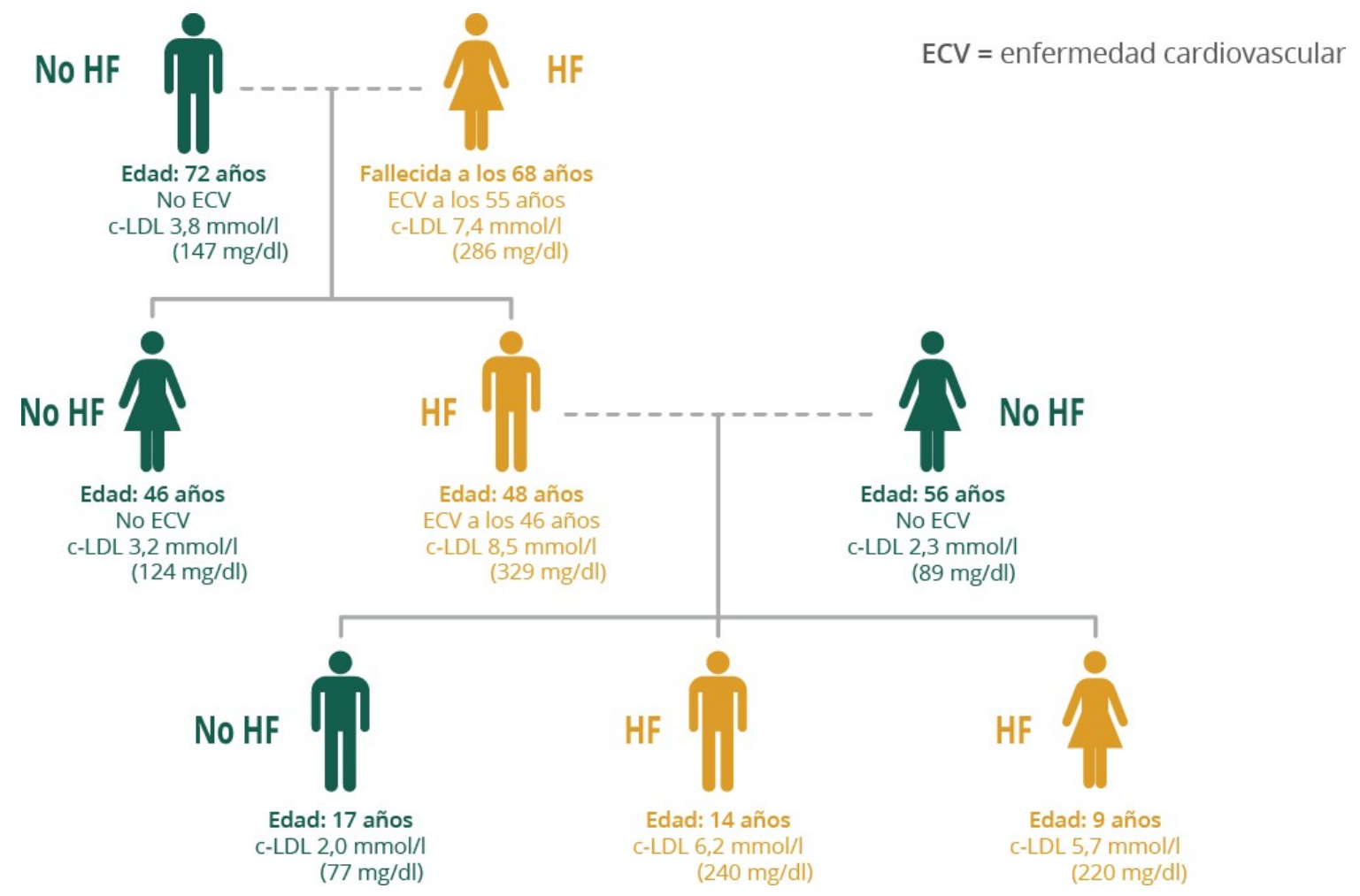

En pocas palabras 
La HF es una enfermedad genética muy frecuente que se transmite de padres a hijos. Las personas afectadas tienen niveles de colesterol alto, debido habitualmente a que el colesterol no es eliminado correctamente en el hígado por una escasez de receptores.

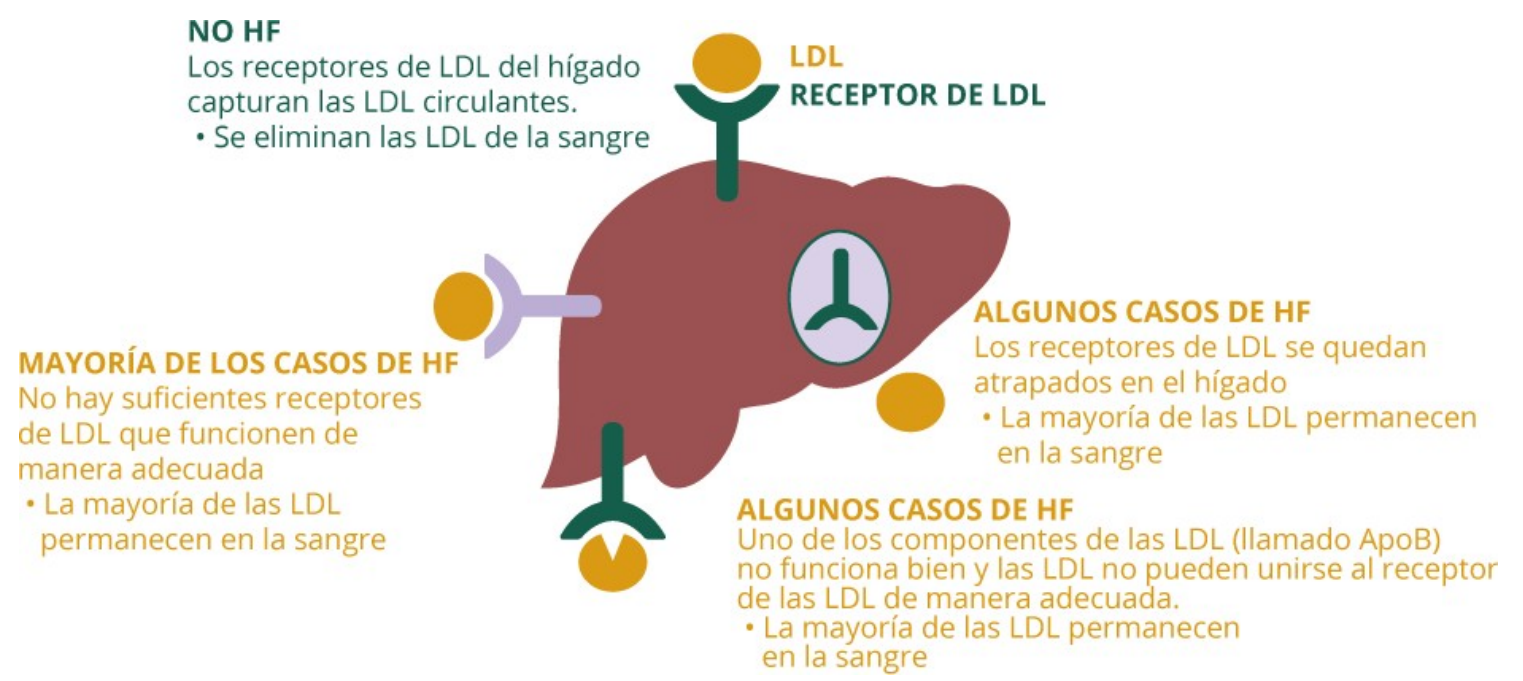

Actualmente, se conocen más de 1.600 mutaciones diferentes a lo largo de todo el gen del rLDL en individuos con hipercolesterolemia familiar procedentes de diversas poblaciones a nivel mundial. Cuando una población se encuentra aislada geográfica o culturalmente, o cuando una gran proporción de personas se encuentra emparentada por descender de antecesores comunes a causa de la migración, podrán existir una o muy pocas mutaciones en un grupo amplio de población. Sin embargo, en otros países como España, donde la población es más heterogénea desde el punto de vista genético, el número de mutaciones suele ser mucho mayor. Hasta la fecha se han reconocido más de 450 mutaciones distintas causantes de HF en España.

La variabilidad en la expresión clínica de la HF en cuanto a las concentraciones de colesterol y el desarrollo de enfermedad cardiovascular, y parte de la respuesta al tratamiento hipolipemiante depende en parte de la mutación del gen del rLDL.

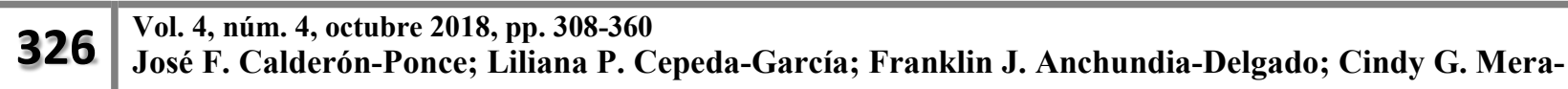
Holguín; César D. Pibaque-Tigua; José E. Anchundia-Baque
} 
En cifras: Hipercolesterolemia Familiar

- 1 de cada 250 personas en la población general presenta HF (190.000 personas en España).

- La enfermedad cardiovascular se manifiesta en más del 50\% de los pacientes con HF antes de los 55 años de edad.

- Una persona afecta de HF, tiene el 50\% de probabilidades de transmitir el gen anormal a sus descendientes, hijos e hijas.

- Se conocen más de 1.600 mutaciones diferentes a lo largo de todo el gen del rLDL relacionadas con la $\mathrm{HF}$.

Además de la Hipercolesterolemia Familiar, cuyo defecto genético está en el gen del rLDL, existen otras causas de hipercolesterolemia familiar que se expresan de forma similar (Tabla 3).

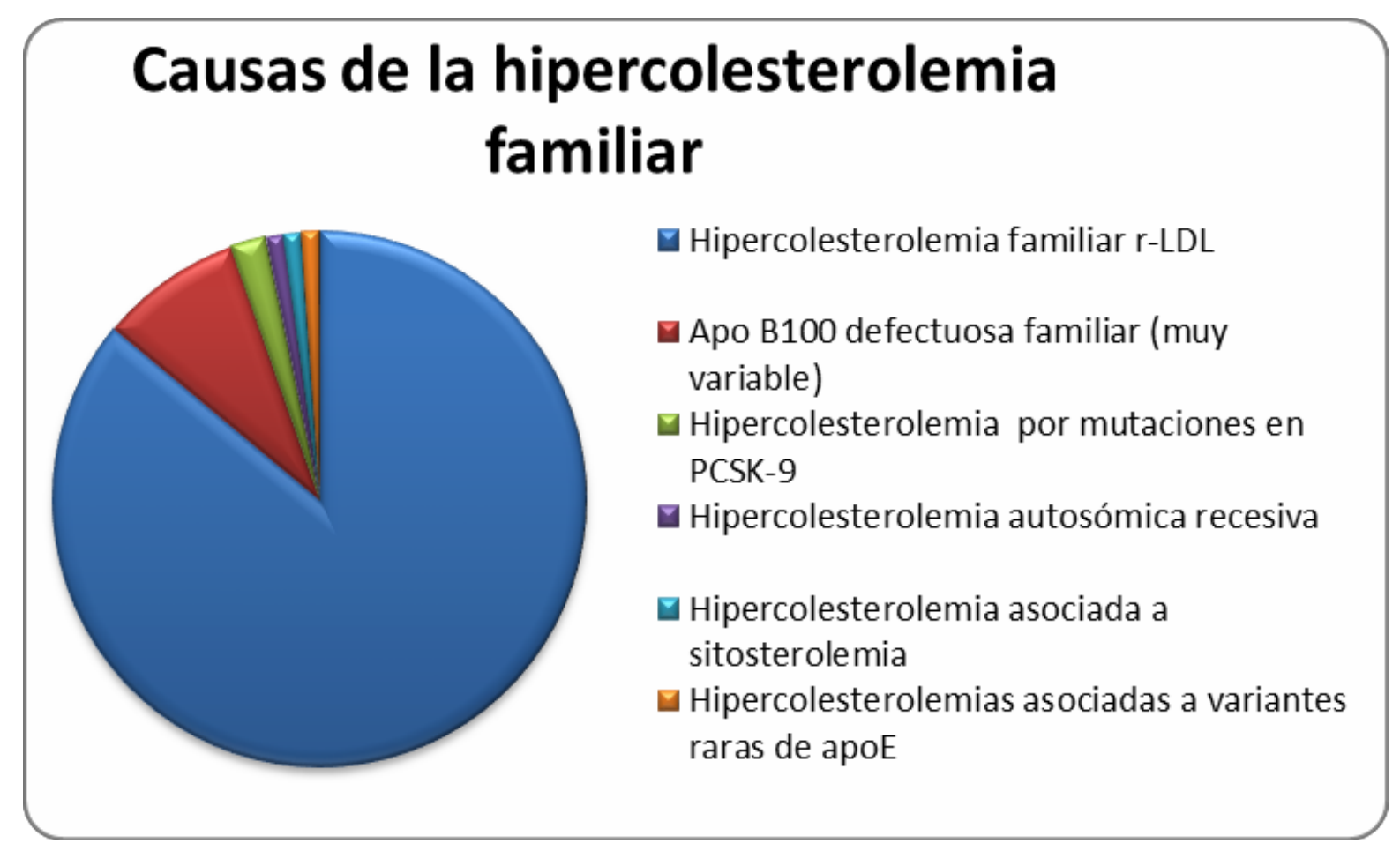

Tabla 3. Frecuencia de hipercolesterolemias familiares autonómicas dominante 
Estas son:

\section{Apo B defectuosa familiar}

La apolipoproteína B (ApoB100) es la única proteína de las LDL y la responsable de unirse al rLDL en el hígado. Los defectos moleculares en el gen de la ApoB100 producen una proteína con una capacidad reducida de unirse al rLDL, por tanto los niveles de c-LDL serán similares a los observados en la HF. Hasta la fecha, se han descrito cuatro mutaciones en este gen asociadas a hipercolesterolemia, la más frecuente, sustituye la Arginina de la posición 3500 por Glutamina y se conoce con el nombre de ApoB3500.

Las características clínicas de esta hipercolesterolemia son prácticamente idénticas a las causadas por defectos en el rLDL, y se conoce como Apo B defectuosa familiar (BDF). Ambas entidades solo pueden distinguirse por el análisis genético.

La mutación apo B3500 es frecuente en países centroeuropeos y poco frecuente en el norte y sur de Europa. Se cree que esta mutación tiene una antigüedad de más de 6000 años y es de origen Celta. En España representa aproximadamente el 4\%-5\% de la población con hipercolesterolemia autosómica dominante. Sin embargo, es una causa frecuente de hipercolesterolemia en la población gallega, probablemente por su origen Celta.

\section{Hipercolesterolemia Asociada a Mutaciones en PCSK9}

Varios estudios han encontrado familias en las cuales a pesar de presentar un fenotipo de HF, el defecto responsable de la hipercolesterolemia no está localizado ni en el gen del rLDL ni en el gen de la apo B100. En el 2003 se describieron algunas mutaciones en el gen de la Proproteína

\footnotetext{
328 Vol. 4, núm. 4, octubre 2018, pp. 308-360 José F. Calderón-Ponce; Liliana P. Cepeda-García; Franklin J. Anchundia-Delgado; Cindy G. MeraHolguín; César D. Pibaque-Tigua; José E. Anchundia-Baque
} 
convertasa subtilisina/kexina tipo 9 (PCSK9) que producen un aumento en la función de esta proteína y se asocia a hipercolesterolemia severa. Esta proteína tiene un papel clave en la degradación de los rLDL hepáticos, y por tanto contribuye a regular los niveles plasmáticos de cLDL. En este sentido, favorece la degradación intracelular de los rLDL, disminuyendo su reciclaje hacia la membrana del hepatocito, lo que ocasiona una reducción del número de receptores y por tanto un aumento en los niveles de colesterol-LDL. En España, aunque se han encontrado casos esporádicos de HF producidas por mutaciones en este gen, es muy infrecuente.

\section{Hipercolesterolemia Autosómica Recesiva (ARH)}

La ARH se produce por mutaciones en la proteína adaptadora del rLDL y tiene un patrón de herencia autosómico recesivo. Los síntomas y niveles de c-LDL son similares a los observados en pacientes con HF homocigota. Ambos progenitores son heterocigotos obligados para el defecto molecular en el gen que codifica la proteína adaptadora, pero por regla general, tienen niveles normales de c-LDL a diferencia de los pacientes con HF homocigota. Este tipo de hipercolesterolemias se asocian también con enfermedad coronaria prematura y xantomas tendinosos.

\section{Sitosterolemia (Hipercolesterolemia Familiar Pseudohomocigota)}

Es un trastorno autosómico recesivo muy poco frecuente, que se caracteriza por aumento en la absorción intestinal de esteroles vegetales, entre los que se encuentra el sitosterol y el colesterol de la dieta, además de eliminar menos colesterol a través de la bilis. Los síntomas clínicos son similares a los de la HF homocigota con una elevada incidencia de enfermedad aterosclerótica prematura y xantomatosis. Por regla general este tipo de pacientes responden bien a la restricción de

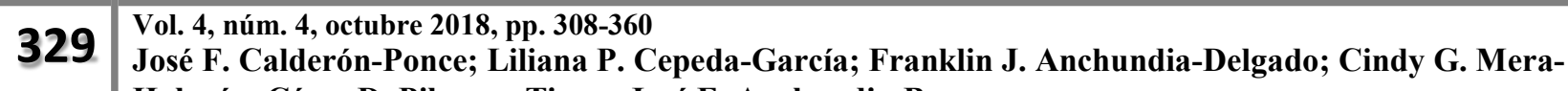
Holguín; César D. Pibaque-Tigua; José E. Anchundia-Baque
} 
los esteroles vegetales de la dieta y al tratamiento con ezetimiba (un inhibidor de la absorción intestinal del colesterol). En España se han descrito solamente unos pocos casos.

En pocas palabras

\begin{tabular}{|c|c|c|}
\hline $\begin{array}{l}\text { ApoB defectuosa } \\
\text { familiar }\end{array}$ & $\begin{array}{l}\text { el colesterol LDL tiene } \\
\text { dificultad para unirse a } \\
\text { su receptor en el higado }\end{array}$ & \\
\hline $\begin{array}{l}\text { Hipercolesterolemia } \\
\text { asociada a } \\
\text { mutaciones en } \\
\text { PCSK9 }\end{array}$ & $\begin{array}{l}\text { el PCSK9 aumenta la } \\
\text { degradación de los } \\
\text { receptores decolesterol } \\
\text { LDL }\end{array}$ & AUMENTAN \\
\hline $\begin{array}{l}\text { Hipercolesterolemia } \\
\text { autosómica recesiva }\end{array}$ & $\begin{array}{l}\text { el receptor de LDL no } \\
\text { puede llevar a cabo su } \\
\text { función de forma } \\
\text { adecuadaporfallosenla } \\
\text { proteina adaptadora }\end{array}$ & $\begin{array}{c}\text { LOS NIVELES } \\
\text { DE C-LDL }\end{array}$ \\
\hline Sitosterolemia & $\begin{array}{l}\text { aumenta la absorción de } \\
\text { colesterol y disminuyesu } \\
\text { eliminación en la bilis }\end{array}$ & \\
\hline
\end{tabular}

Es la forma más común de hipercolesterolemia primaria y es la consecuencia de la interacción entre numerosos genes y factores ambientales, especialmente una alimentación inadecuada. La coincidencia en una misma persona de varios genes que tienden a inducir elevaciones moderadas del colesterol plasmático daría lugar a una hipercolesterolemia poligénica (HP). Su frecuencia es de aproximadamente un 4\% de la población adulta, estimándose que en España, más de un millón de personas pueden tener una HP.

\section{Diagnóstico}


El diagnóstico debe sospecharse en cualquier persona con cifras de colesterol de 260 a 320 mg/dl y con concentraciones de triglicéridos normales. Se puede asociar con hipertensión, obesidad y/o diabetes con el consiguiente aumento de desarrollar una enfermedad cardiovascular

(Tabla 4).

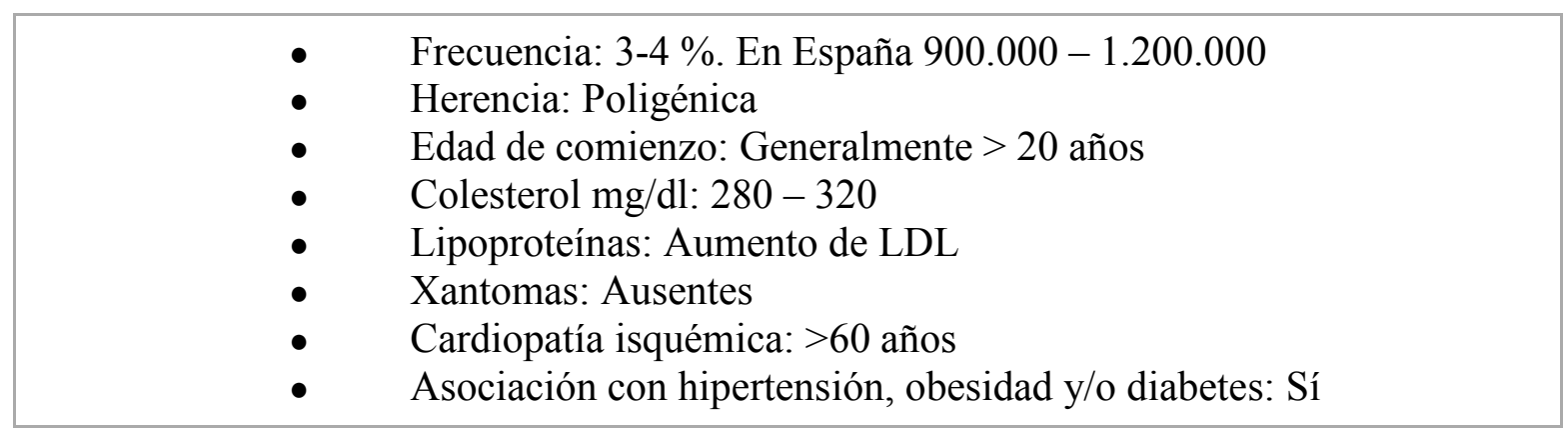

Tabla 4: Principales características de la Hipercolesterolemia Poligénica

Un 20\% de los casos con HP pueden tener historia familiar de enfermedad coronaria prematura y suele ser frecuente la agregación familiar de hipercolesterolemia.

Generalmente, en las familias de las personas afectadas la distribución media de las concentraciones de colesterol están más elevadas que en la población normal. Las personas jóvenes con hipercolesterolemia poligénica pueden tener las concentraciones de colesterol normales o ligeramente elevadas y la hipercolesterolemia se suele expresar generalmente por encima de los 20 años.

\section{Tratamiento de las hipercolesterolemias familiares}

Los pacientes con HF constituyen una población con un elevado riesgo para el desarrollo prematuro de enfermedad coronaria. Una detección precoz puede prevenir miles de infartos de

\footnotetext{
331 Vol. 4, núm. 4, octubre 2018, pp. 308-360

José F. Calderón-Ponce; Liliana P. Cepeda-García; Franklin J. Anchundia-Delgado; Cindy G. MeraHolguín; César D. Pibaque-Tigua; José E. Anchundia-Baque
} 
miocardio anuales con un considerable ahorro en el gasto social y sanitario. La omisión en la detección de personas con tan grave trastorno puede tener graves consecuencias tanto personales como sanitarias.

Una vez realizado el diagnóstico, es importante que los pacientes conozcan que el peligro de sufrir un infarto de miocardio precoz es elevado y que se puede reducir cuando reciben tratamiento farmacológico de forma regular. El tratamiento de las hipercolesterolemias familiares debe incluir tanto el manejo de la hiperlipemia como el de los demás factores de riesgo. La corrección del sobrepeso, la supresión del alcohol cuando existe aumento de triglicéridos, el realizar ejercicio físico y una dieta baja en grasas saturadas y colesterol suelen ser medidas que ayudan a corregir la hiperlipemia. Prácticamente, todos los pacientes con una hipercolesterolemia familiar requerirán tratamiento farmacológico para reducir el colesterol y/o los triglicéridos; ya que las medidas higiénico-dietéticas no suelen ser suficientes para controlar los niveles de colesterol y triglicéridos. Las estatinas en monoterapia o en combinación con ezetimiba o resinas secuestradoras de ácidos biliares son el tratamiento de elección cuando predomina la hipercolersterolemia; en cambio, en aquellas personas con predominio de triglicéridos, los fibratos son fármacos muy útiles. La asociación de estatinas y fibratos a dosis bajas es una combinación muy eficaz cuando no conseguimos controlar la hiperlipemia mixta o Hiperlipemia Familiar Combinada con un solo fármaco.

Actualmente se ha demostrado que la disminución de las concentraciones de colesterol reduce el riesgo de presentar un infarto de miocardio, angina de pecho, ictus y de muerte por enfermedad cardiovascular. Para el tratamiento de las hipercolesterolemias familiares existen medidas no farmacológicas y farmacológicas. 
En cifras: objetivos de C-LDL en HF

\section{Objetivos recomendados en adultos y en niños con HF}
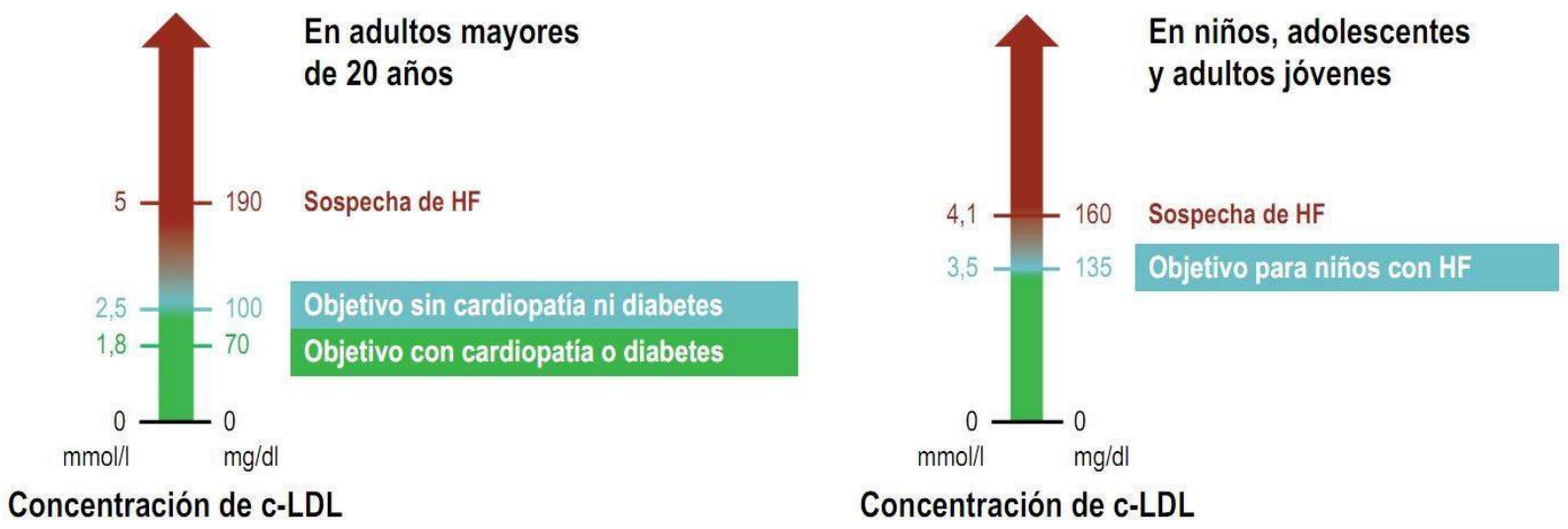

Los pacientes con HF requieren bajar sus niveles de colesterol a niveles más estrictos que los de la población general.

Organizaciones de Apoyo en la Hipercolesterolemia Familiar

Recientemente se han publicado los datos sobre "Grupos de apoyo y defensa en pacientes con Hipercolesterolemia Familiar (HF): una perspectiva multinacional" con una serie de contribuciones de organizaciones de pacientes con HF de Canadá, Estados Unidos, España y Reino Unido junto con la organización de pacientes Europea. La publicación revela que para la defensa y apoyo de los pacientes la unión con los profesionales sanitarios y la colaboración entre organizaciones son esenciales para conseguir los cambios necesarios en el apoyo y cuidado de la población con HF en el mundo. 
El informe, publicado en una edición especial de la revista Atherosclerosis con motivo del Día Internacional de concienciación sobre la HF, se basa en el trabajo de cinco organizaciones de pacientes desde un objetivo inicial de apoyo, centralizado en la concienciación y educación sobre la enfermedad, compartiendo consejos sobre hábitos de vida saludables así como de detección precoz y registros que puedan conducir a un mejor cuidado de la HF. La eficacia de trabajar juntos como una comunidad de pequeñas y grandes organizaciones y compartir experiencias junto con la colaboración de los profesionales sanitarios puede contribuir a un mejor conocimiento de la HF a nivel global. Este informe ha contado con la contribución de la Fundación Hipercolesterolemia Familiar (FHF) de España a través de Teresa Pariente y Raquel Arroyo, secretaria general y nutricionista respectivamente.

En el informe se destaca que las decisiones de los gobiernos de salud pueden afectar las vidas de los pacientes con HF tanto de una forma positiva como negativa. Por esto, los representantes de las organizaciones de pacientes necesitan expresar en sus propias palabras, como las decisiones que se toman por los gobiernos de salud pueden tener un impacto en las vidas de las personas con HF. Por tanto, las organizaciones de pacientes necesitan ser escuchadas por los que toman las decisiones en salud, y evitar la inequidad que se sigue produciendo con la HF, a pesar de ser un trastorno genético muy frecuente.

También se destaca el papel de las organizaciones de pacientes en la detección de las familias, en el desarrollo de registros a nivel nacional, así como en la monitorización y en la información a los gobiernos para que se implementen los nuevos tratamientos. En este sentido, el informe describe el modelo de un programa de cribado genético en cascada familiar para la detección de la HF realizado en España por la FHF. Y se destaca como se realiza el mencionado

\footnotetext{
334 Vol. 4, núm. 4, octubre 2018, pp. 308-360 José F. Calderón-Ponce; Liliana P. Cepeda-García; Franklin J. Anchundia-Delgado; Cindy G. MeraHolguín; César D. Pibaque-Tigua; José E. Anchundia-Baque
} 
programa a través de las "jornadas de detección de fin de semana", que realiza la FHF y que básicamente consisten en la identificación de unas 120-140 personas (una media de 5 casos por familia) en los centros hospitalarios que colaboran en este proyecto. Las personas detectadas se incluyen en el Estudio SAFEHEART (Estudio de Cohorte longitudinal de Hipercolesterolemia Familiar en España) que cuenta con más de 5.000 casos para un mejor seguimiento y control.

La información derivada del mencionado estudio ha dado lugar al desarrollo de una ecuación para estimar el riesgo individual de nuevos eventos cardiovasculares a 5 y 10 años en los pacientes con HF. Por otra parte, la FHF ha realizado un estudio económico de un Plan Nacional de Detección de la HF en España a solicitud del Ministerio de Sanidad para su posterior aprobación y sus resultados confirman que el mencionado Plan, además de salvar vidas, produce un importante ahorro económico.

\section{Mejorando la atención global de la hipercolesterolemia familiar}

Recientemente se han publicado los datos de una encuesta sobre la situación de la Hipercolesterolemia Familiar (HF) en 63 países de todo el mundo entre ellos España. La encuesta destaca que el colesterol elevado es más común de lo que se piensa. La HF aún está muy infradiagnosticada. Y su detección y tratamiento varía ampliamente a través de los diferentes países. El tratamiento de la HF no es universalmente re-embolsado y el acceso a los nuevos fármacos antiPCSK9 y la aféresis suele estar limitado en numerosos países.

El informe, publicado en una edición especial de la revista Aterosclerosis, revela la falta de información sobre la enfermedad y los vacíos en su detección y tratamiento. Desde 2015, investigadores de unos 70 países se han unido, creando una red internacional promovida por la

\footnotetext{
335 Vol. 4, núm. 4, octubre 2018, pp. 308-360 José F. Calderón-Ponce; Liliana P. Cepeda-García; Franklin J. Anchundia-Delgado; Cindy G. MeraHolguín; César D. Pibaque-Tigua; José E. Anchundia-Baque
} 
Sociedad Europea de Ateroesclerosis y un registro global de HF, que incluye a más de 11,000 pacientes en todo el mundo. En este registro participa España a través de la Fundación Hipercolesterolemia Familiar.

Esta nueva publicación tiene varios mensajes importantes para todos aquellos involucrados en el cuidado y las políticas de salud de la HF. En primer lugar, sigue habiendo una falta general de información sobre la prevalencia de HF en la mayoría de los países. Si bien generalmente se acepta que aproximadamente una de cada 200-300 personas en la población general tienen HF.

En segundo lugar, la encuesta destaca que la HF aún está muy infra-diagnosticada. En la mayoría de los 63 países, el diagnóstico clínico de HF se basa en los criterios de la red holandesa de las Clínicas de Lípidos. Si bien están bien validados, pueden no ser apropiados en todas las poblaciones y regiones, lo que destaca la necesidad real de criterios de diagnóstico ajustados por país para la HF.

En tercer lugar, los resultados de la encuesta subrayan que la financiación sigue siendo un obstáculo importante para la mejor atención en la HF. Esta falta de fondos afecta a todos los aspectos de la atención de la $\mathrm{HF}$, incluido el acceso a pruebas genéticas y tratamientos, no solo a terapias novedosas como inhibidores de PCSK9 y aféresis de lipoproteínas, sino también estatinas y ezetimiba en algunos países.

Los investigadores también descubrieron que solo algunos países cuentan con capacidades adecuadas para la detección genética. Así, algunos de los programas cuentan con apoyo local o regional en lugar de a nivel nacional. Y con frecuencia, en numerosos países carecen de apoyo.

\footnotetext{
336 Vol. 4, núm. 4, octubre 2018, pp. 308-360 José F. Calderón-Ponce; Liliana P. Cepeda-García; Franklin J. Anchundia-Delgado; Cindy G. MeraHolguín; César D. Pibaque-Tigua; José E. Anchundia-Baque
} 
La HF es una condición hereditaria que hace que las personas tengan niveles de colesterol LDL más altos de lo normal desde el nacimiento, que les expone a un mayor riesgo de enfermedad cardiovascular si no se tratan con medicamentos reductores del colesterol, como las estatinas.

Incluso si una persona tiene un estilo de vida saludable, tener HF significa que aún puede tener un riesgo mucho mayor de obstrucción de las arterias y enfermedad cardiovascular prematura. Cuanto antes podamos identificar a las personas con HF, antes podremos intervenir para prevenir la enfermedad cardiovascular.

En España, se estima que al menos el 20\% de los casos con HF están diagnosticados y aproximadamente un $30 \%$ de estos tienen diagnóstico genético. Además, todos los tipos de tratamiento farmacológico y la LDL-aféresis están disponibles. En España se está pendiente de aprobar una Estrategia de Detección de la HF con la participación de médicos especialistas y de atención primaria. Esta estrategia es coste-eficaz de acuerdo con un estudio publicado en 2017.

\section{Glosario de términos}

ADN (Ácido desoxirribonucleico)

Molécula que codifica los Genes responsables de la estructura y la función de un organismo y posibilita la transmisión de información Genética de una Generación a la siguiente.

\section{Afectado}

Individuo que manifiesta síntomas de una enfermedad o patología determinada.

\footnotetext{
337 Vol. 4, núm. 4, octubre 2018, pp. 308-360
José F. Calderón-Ponce; Liliana P. Cepeda-García; Franklin J. Anchundia-Delgado; Cindy G. MeraHolguín; César D. Pibaque-Tigua; José E. Anchundia-Baque
} 


\section{Alteración de la secuencia}

Cualquier alteración producida en el ADN o más concretamente en un Gen con respecto a su estado natural; puede no tener repercusión clínica (en cuyo caso se denomina Generalmente “Polimorfismo"), con repercusión clínica en cuyo caso se considera mutación), o ser de significado desconocido.

Análisis de secuencias

Proceso mediante el cual se determina la secuencia de nucleótidos en un segmento de ADN.

\section{Análisis del origen parental}

Análisis utilizado para especificar si un individuo ha heredado determinado Cromosoma o segmento de ADN de la madre o del padre. Resulta importante en el diagnóstico de enfermedades relacionadas con la Impronta genética o causadas por disomía uniparental.

\section{Análisis directo del ADN}

Uso de cualquier técnica, por ejemplo, análisis de secuencias, rastreo de mutaciones o análisis mutacional, para detectar variantes en un Gen.

\section{Angina de pecho}

Es la expresión de la falta de aporte de sangre a las células del corazón (isquemia miocárdica). Se manifiesta por una sensación de dolor, opresión o malestar característico que generalmente se inicia en el centro del pecho y que puede extenderse principalmente a los brazos, el cuello, la espalda y la mandíbula. El dolor es de intensidad progresiva y duración limitada y suele

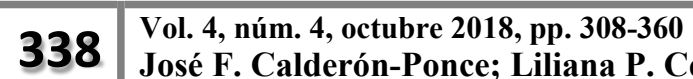
José F. Calderón-Ponce; Liliana P. Cepeda-García; Franklin J. Anchundia-Delgado; Cindy G. MeraHolguín; César D. Pibaque-Tigua; José E. Anchundia-Baque
} 
desencadenarse en estados que requieren un aumento del trabajo del corazón. El ejercicio, el trabajo, la actividad sexual y las emociones son situaciones todas ellas, que aumentan las necesidades de oxígeno del miocardio. La angina desaparece de forma espontánea cuando cesa la causa que la desencadena. Esta situación puede mantenerse estable durante largo tiempo y presentarse de nuevo el dolor si se realiza la misma actividad y no se han modificado, o han progresado las lesiones de las arterias coronarias. En algunas ocasiones la crisis de angina aparece en reposo. En este caso lo que ocurre es un estrechamiento o espasmo de la arteria que dificulta el paso de la sangre.

\section{Angioplastia coronaria}

Es un procedimiento que se realiza mediante un cateterismo, pero en este caso la finalidad no es diagnóstica sino terapéutica. Se trata de dilatar aquellas zonas de las arterias coronarias que presentan lesiones obstructivas graves. Existen dos procedimientos. La dilatación con balón, que consiste en hinchar súbitamente y con alta presión un globo que rompe la placa de ateroma y mejora la permeabilidad de la arteria. La implantación de un stent, que consiste en colocar en el lugar de la lesión un muelle de metal que, al liberarse, se expande y rompe la placa (ateroma), por lo que impide que vuelva a cerrarse la luz de la arteria. En ocasiones, el stent se implanta después de dilatar el vaso con el globo-balón y, en otros casos, se pone directamente.

\section{Anticoagulantes}

Son fármacos que reducen el riesgo de ataques al corazón y de ataques cerebrales al disminuir la formación de coágulos sanguíneos en sus arterias y venas. Siempre bajo prescripción médica.

\footnotetext{
339 Vol. 4, núm. 4, octubre 2018, pp. 308-360 


\section{Apolipoproteina B}

Es una proteína que forma parte de las lipoproteínas que transportan lípidos como colesterol en la sangre, especialmente las LDL (lipoproteínas de baja densidad).

\section{Árbol genealógico / Genealogía / Árbol familiar}

Diagrama que representa las relaciones Genéticas y la historia clínica de una familia, por medio de símbolos y terminología estándar.

Términos relacionados: consanguinidad; consultante; portador obligado; probando.

\section{Arco corneal}

El arco corneal es un anillo blanco pálido parcial o completo alrededor del iris (la parte que da color al ojo). Tiene valor diagnóstico de HF cuando se presenta antes de los 45 años.

\section{Arterioesclerosis}

Es una lesión que se produce por el depósito en la pared de la arteria de determinadas sustancias como el colesterol, calcio y elementos celulares, en forma de acúmulos localizados (placas de ateroma) que estrechan la luz de la arteria.

La formación de las placas de ateroma no tiene relación directa con la edad. En algunas personas aparece muy pronto y, en otras, no se produce nunca. Su aparición está relacionada con la presencia de factores de riesgo cardiovascular, como en las Hipercolesterolemias Familiares. 


\section{Asesoramiento genético}

Proceso que implica a un solo individuo o a una familia entera, que comprende: Información o evaluación del posible origen genético de una enfermedad, o la identificación de aspectos relacionados con el tratamiento médico, cálculo e información sobre los riesgos genéticos, prestación de apoyo psicosocial o recomendación a otros profesionales.

Ateroma

La placa de ateroma se produce por acúmulos de colesterol y elementos celulares, que se depositan en la pared de la arteria, estrechando el calibre o luz del vaso.

\section{Autosómico}

Se refiere a cualquiera de los cromosomas que no son los determinantes del sexo (es decir, $\mathrm{X}$ e Y) o a los genes de esos cromosomas.

\section{Autosómico dominante}

Término que se utiliza para describir un rasgo o patología cuyo Fenotipo está expresado en los individuos que han heredado una sola copia de una Mutación génica determinada (Heterocigotos); se refiere específicamente a un Gen de uno de los 22 pares de autosomas (cromosomas no sexuales).

\section{Autosómico recesivo}

Término que se utiliza para describir un rasgo o patología que requiere la presencia de dos copias de una Mutación de un Gen en un Locus determinado para que se exprese el Fenotipo

\footnotetext{
341 Vol. 4, núm. 4, octubre 2018, pp. 308-360 
observable; se refiere específicamente a los genes de uno de los 22 pares de autosomas (Cromosomas no sexuales).

Balón

Se utiliza para romper la placa de ateroma, dentro de una de las técnicas utilizadas en la angioplastia, que consiste en hinchar súbitamente y con alta presión un globo que rompe la placa de ateroma y mejora la permeabilidad de la arteria (ver angioplastia).

\section{Betabloqueantes}

Este tipo de fármacos ayudan a regular y disminuir el ritmo cardíaco y se utilizan en el control de determinadas arritmias. También se utilizan estos medicamentos para aliviar el dolor en el pecho, así como para prevenir la repetición de infartos. Siempre bajo prescripción médica.

Bypass cirugía de revascularización coronaria

El bypass sigue siendo, aún con la alternativa de la angioplastia la mejor opción para algunos pacientes. En esencia, es un medio de "puentear" la zona obstruida, de forma que la sangre que no puede pasar normalmente por la arteria lesionada se desvía por el injerto-puente y llega hasta terrirorios que antes padecían isquemia (falta de oxígeno por falta de riego). Los puentes tradicionales se hacen con vena safena, que se extrae de la pierna del paciente, y también con arteria. El trozo de vena se une a la arteria aorta, por un lado, y a la arteria coronaria dañada después del sitio obstruido por otro.

\section{Cascada familiar screening}


Una vez conocido el resultado genético positivo del Caso Índice, se estudiará ese mismo defecto genético o mutación, en el resto de los familiares. Esto es lo que se denomina detección en cascada.

Caso Índice, o probando

Es el primer caso estudiado en una familia con resultado genético positivo de Hipercolesterolemia Familiar. A partir de este caso positivo, se buscará el resultado genético obtenido -mutación- en el resto de los familiares.

\section{Cateterismo cardíaco}

Se trata de una técnica que proporciona una información muy precisa sobre el funcionamiento del corazón. Se introducen unos finos tubos de plásticos, llamados catéteres o sondas a través de la piel en el torrente circulatorio, en una vena o una arteria hasta llegar al corazón. Posteriormente se inyecta contraste en el ventrículo izquierdo para estudiar los distintos segmentos que lo forman.

Por un lado nos va a permitir conocer la presión que existe en la arteria aorta y en las cavidades del corazón y por otra, la cantidad de sangre que este bombea. También nos permite observar el movimiento de sus paredes y el tamaño de las cavidades.

\section{Colesterol bueno}

¿Por qué se dice que los niveles de HDL indican el "colesterol bueno"?

\footnotetext{
343 Vol. 4, núm. 4, octubre 2018, pp. 308-360 
Este tipo de lipoproteína transportadora de colesterol (HDL), se encarga de eliminar el exceso de colesterol depositado en las paredes arteriales, y llevarlas de nuevo al hígado, para ser reutilizadas o excretadas.

\section{Colesterol malo}

¿Por qué se dice que los niveles de LDL indican el "colesterol malo"?

Cuando el organismo acumula colesterol en exceso, cierta cantidad puede quedar depositada (LDL) en las paredes internas de las arterias, dañándolas, e incluso, llegando a obstruir completamente su luz. Este proceso se conoce como ateroesclerosis y cuando ocurre, puede producirse un infarto miocárdico o cerebral.

\section{Coronariografía o Arteriografía}

La técnica requerida es muy parecida a la del cateterismo. Y nos permite conocer el estado de las arterias coronarias. Es imprescindible cuando la angina de pecho no se controla con fármacos, o cuando la severidad de los síntomas, como el fallo cardíaco así lo aconsejan. Se introduce un catéter que llega a las arterias coronarias. A continuación se inyecta contraste y se graba en una película para su correspondiente estudio.

\section{Desfibrilador automático implantable (DAI)}

Es el medio más moderno y eficaz de tratar las arritmias graves. Consiste en un marcapasos que es capaz de detectar las arritmias más graves (taquicardias ventriculares y fibrilación ventricular) y proporcionar una pequeña descarga eléctrica que las elimina.

\footnotetext{
344 Vol. 4, núm. 4, octubre 2018, pp. 308-360 José F. Calderón-Ponce; Liliana P. Cepeda-García; Franklin J. Anchundia-Delgado; Cindy G. MeraHolguín; César D. Pibaque-Tigua; José E. Anchundia-Baque
} 


\section{Disnea}

Es la dificultad para respirar o sensación de falta de aire. Las causas suelen ser afecciones broncopulmonares o cardiacas. Entre las afecciones pulmonares destacan: el asma bronquial, la bronquitis crónica y el enfisema pulmonar. Entre las causas cardíacas están: la insuficiencia cardiaca de cualquier etiología. La disnea suele ser progresiva. Su comienzo puede deberse a grandes esfuerzos para acabar manifestándose en estado de reposo.

\section{Ecocardiograma}

La ecocardiografía es una de las técnicas más útiles para evaluar el funcionamiento del corazón y el estado de las válvulas cardíacas. No permite visualizar las arterias coronarias. Se puede hacer sin ningún riesgo para el paciente. El fundamento de la ecografía, similar al radar o el sónar, es la emisión de ondas sonoras inocuas y fáciles de interpretar, que rebotan en las estructuras y permiten crear imágenes de una altísima fidelidad.

\section{Electrocardiograma}

El corazón produce una pequeña corriente eléctrica en cada latido. Esta corriente puede registrarse mediante un aparato denominado electrocardiógrafo. Y el dibujo que se obtiene se llama electrocardiograma. El trazado de este dibujo puede verse modificado por algunas alteraciones del corazón, como la disminución del riego sanguineo en un determinado territorio (isquemia). Esta prueba es útil en los episodios agudos de la enfermedad coronaria. En el infarto de miocardio permite reconocer con bastante aproximación su localización y tamaño. Sin embargo, en muchos enfermos en fase crónica de la enfermedad, el trazado es normal cuando se obtiene en reposo y sólo se modifica cuando el enfermo experimenta dolor. El Eco-Doppler es un complemento

\footnotetext{
345 Vol. 4, núm. 4, octubre 2018, pp. 308-360 
relativamente reciente de la ecografía. Permite estudiar los flujos de sangre, con lo que se puede detectar anomalías en los circuitos cardíacos, obstrucciones al paso de la sangre, alteraciones en la función de las válvulas cardíacas, etc.

\section{Enfermedad cardiovascular}

Se produce por la presencia de ateroesclerosis y el consiguiente estrechamiento de las paredes de las arterias. Si la ateroesclerosis se localiza en las arterias coronarias (enfermedad coronaria), si se localiza en las arterias que llevan sangre al cerebro (enfermedad cerebrovascular) y enfermedad o arteriopatia periférica cuando es a nivel periférico (aorta, iliacas y otras arterias que llevan sangre a las extremidades inferiores, así como otras arterias que también llevan sangre al aparato digestivo y al riñón).

\section{Enfermedad coronaria}

La enfermedad cardiovascular (ECV) prematura, especialmente la coronaria (infarto de miocardio, angina de pecho, etc), es la manifestación clínica más grave de la HF. Se trata del proceso de estrechamiento y bloqueo posterior de las arterias coronarias, que son las que transportan la sangre hasta el músculo cardiáco. Al interrumpirse el paso de sangre, las células del miocardio mueren, dando lugar al infarto de miocardio.

La principal consecuencia de la enfermedad coronaria es la incapacidad de las arterias coronarias para llevar el oxígeno necesario a un determinado territorio del músculo cardiaco, lo que dificulta su funcionamiento. De este modo el corazón enferma por la mala función del sistema de irrigación. La causa más frecuente de alteración de las coronarias es la arterioesclerosis. Este daño se produce por el depósito en la pared de la arteria de determinadas substancias como el colesterol,

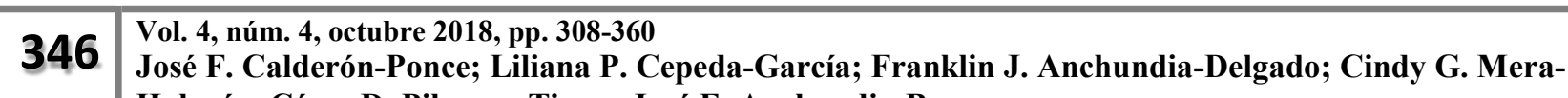
Holguín; César D. Pibaque-Tigua; José E. Anchundia-Baque
} 
calcio y elementos celulares en forma de acúmulos localizados - placas de ateroma- que estrechan el calibre o luz de la arteria.

Ergometría/Test de esfuerzo

Sirve para determinar el nivel de esfuerzo que puede tolerar el corazón. Y también como ayuda en el diagnóstico correcto de la isquemia coronaria. Esta prueba es muy útil para valorar la eficacia del tratamiento en la cardiopatía isquémica.

\section{Estatinas}

Son el fármaco de elección para el tratamiento de la Hiperclesterolemia, también conocidos como inhibidores de la $\mathrm{HMG}$ CoA reductasa. Estos fármacos bloquean una enzima específica que controla la producción del colesterol, no sólo reduciendo el colesterol que fabrica el hígado, sino que aumentan la función de los receptores LDL, en la eliminación del colesterol de la circulación sanguínea. Dependiendo de la estatina y de la dósis pueden bajar el colesterol "malo", o LDL entre un $25-60 \%$. Entre las diferentes estatinas se encuentrarn: lovastatina, pravastatina, simvastatina, fluvastatina, artorvastatina, rosuvastatina y pitavastatina.

\section{Estudio genético de HF}

La prueba definitiva, o diagnóstico de certeza para identificar la Hipercolesterolemia Familiar (HF) es la determinación genética o estudio genético. Son métodos basados en el análisis de ADN del gen del receptor de LDL y otros genes que también producen una HF. Se recomienda en las distintas guías nacionales e internacionales sobre la HF.

\footnotetext{
347 Vol. 4, núm. 4, octubre 2018, pp. 308-360 
Evaluación del riesgo

Cálculo por medio de ecuaciones matemáticas apropiadas del riesgo de que un individuo haya heredado una Mutación génica determinada, de que desarrolle un trastorno específico, o de que tenga un hijo con un trastorno determinado. El cálculo se basa en el análisis de múltiples factores, incluyendo la historia clínica Familiar y los antecedentes étnicos entre otros.

Factores de riesgo

Un factor de riesgo para la enfermedad cardiovascular es aquello que aumenta la posibilidad de presentarla. Algunos factores de riesgo como la edad, el sexo, los genes, no podemos cambiarlos; sin embargo, existen otros factores de riego como sobrepeso, obesidad, tabaco, diabetes, hipertensión, inactividad física, que sí los podemos cambiar.

\section{Farmacogenética}

En definición de Allen D. Roses, es el estudio de las diferencias genéticas que influencian la variabilidad individual en la respuesta a los fármacos. También la herramienta clave que permite predecir la respuesta a un fármaco basado en la constitución genétia del paciente, así como diseñar nuevos fármacos en base a la informació genética.

\section{Farmacogenómica}

Trata de indentificar nuevas dianas terapéuticas mediante herramientas genómicas. Su objetivo es la creación de fármacos a medida para cada paciente y adaptados a sus condiciones genéticas. El medio ambiente, la dieta, el estilo de vida y el estado de salud influyen sobre la respuesta de una persona a un fármaco. 


\section{Fibrilación auricular}

La fibrilación auricular se produce cuando las señales eléctricas del corazón fallan y provocan la contracción (obstrucción) rápida e irregular de las cámaras superiores del corazón (las aurículas). De esta forma los latidos se vuelven irregulares y no permiten el bombeo de la sangre hacia las cámaras inferiores del corazón (los ventrículos) y como consecuencia la sangre se acumula e impide el bombeo eficaz del corazón. Sus síntomas más probables de la fibrilación auricular son las palpitaciones, el mareo, el dolor de pecho y la dificultad respiratoria, aunque en algunas situaciones es asintomática.

Gen - ¿Qué son los genes?

Los genes son las instrucciones que nuestro cuerpo necesita para expresar su correcto funcionamiento. Nuestros cuerpos están formados por millones de células y cada una de ellas contiene una copia de todos nuestros genes. Algunos genes pueden originar determinados procesos y otros pueden detenerlos. Los genes imitan largas cadenas de letras que se separan. A veces en esa cadena se producen errores al igual que cuando escribimos, pero cuando esto sucede puede cambiar la forma de trabajar de ese gen y producir un defecto como en el caso de la HF.

\section{Genética}

El biólogo británico William Beteson acuñó en 1905 el término genetics. Dos años antes se había descubierto la implicación de los cromosomas en la herencia. Y un sigo después se completaba con éxito el Proyecto Genoma Humano.

\section{Genómica}

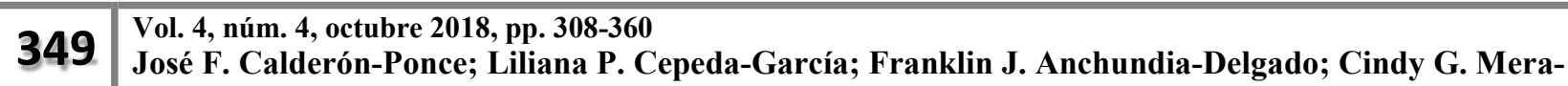
Holguín; César D. Pibaque-Tigua; José E. Anchundia-Baque
} 
En Medicina, es el estudio de la estructura genética del individuo. La medicina individualizada utiliza la información genómica para mejorar el diagnóstico de la enfermedad, su prevención y tratamiento.

\section{Holter}

Consiste en registrar un electrocardiograma de 24 a 48 horas de duración en una grabadora que se lleva colocada en la cintura y va conectada a unos cables (electrodos) pegados en el pecho. Esta información recogida en la grabación se analizará adecuadamente. Al colocar el holter al paciente, también se le entregará una hoja-diario con sus datos personales, en la que deberá anotar la hora en la que se producen determinados síntomas, tales como dolor, mareo o palpitación. Este método es de gran ayuda para el diagnóstico de arritmias y en determinadas formas de angina de pecho.

\section{Ictus (trombosis o infarto cerebral)}

Se trata de una enfermedad cerebrovascular que afecta a los vasos sanguíneos que suministran sangre al cerebro. También se la conoce como Accidente Cerebro Vascular (ACV), embolia o trombosis. Los dos últimos términos, no obstante, se refieren más bien a las distintas causas del ictus. Ocurre cuando un vaso sanguíneo que lleva sangre al cerebro se rompe o es taponado por un coágulo o una placa de ateroesclerosis. Debido a esta ruptura o bloqueo, parte del cerebro no consigue el flujo de sangre que necesita. La consecuencia es que las células nerviosas del área del cerebro afectada no reciben oxígeno, por lo que no pueden funcionar y mueren transcurridos unos minutos.

Signos de un problema cerebro vascular (ictus trombosis o infarto cerebral): 
- Debilidad o falta de sensibilidad súbita de la cara, brazo o pierna en un lado del cuerpo.

- Pérdida o debilidad repentina de la visión, especialmente en un ojo.

- Pérdida del habla o problemas al hablar o entender.

- Fuertes dolores de cabeza de forma súbita sin causa aparente.

- Vértigos, pérdida de equilibrio o caídas repentinas inexplicables, junto con cualquiera de los síntomas mencionados.

En cualquier caso, consiga ayuda médica enseguida.

\section{Infarto de miocardio}

Se trata de una situación aguda y grave que ocurre como consecuencia de la obstrucción de una arteria coronaria por un trombo (un coágulo de sangres que se forma sobre una placa de ateroma) y ello impide el paso de la sangre. La consecuencia final de la obstrucción de la arteria es la muerte (necrosis) del territorio que irriga la arteria obstruida. Por tanto, la importancia del infarto de miocardio depende de la cantidad de músculo cardiaco que se necrosa y está en relación con el lugar en el que se produce la obstrucción y condición de la arteria. El infarto es habitualmente un episodio inesperado. A diferencia de la angina de pecho, no suele tener relación con circunstancias desencadenantes externas, como por ejemplo la actividad física. Además, se puede presentar tanto en personas previamente sanas (pero que habitualmente tienen factores de riesgo) como en pacientes que ya han padecido alguno de los signos de esta enfermedad. Un episodio de infarto se manifiesta por un dolor en el pecho de similares características a la angina pero que se mantiene durante más de 30 minutos. El infarto puede ocurrir en reposo y el dolor no calma espontáneamente. Suele ir acompañado de sudoración, nauseas, vómitos y sensación de angustia. Afortunadamente el corazón

\footnotetext{
351 Vol. 4, núm. 4, octubre 2018, pp. 308-360 
tiene una capacidad de reserva importante y, después de la mayoría de los infartos de miocardio, el músculo cardíaco que permanece sano puede realizar el trabajo de bombeo necesario para que el paciente pueda llevar una vida perfectamente normal.

Signos de un infarto:

- Presión torácica con sensación de malestar y de estar lleno.

- Dolor aplastante u opresivo en el centro del pecho durante varios minutos.

- Opresión que empieza en el centro del pecho y se irradia a los hombros, cuello o brazos.

- Malestar torácico con sensación de mareo, sudoración, náuseas o dificultad para respirar.

En cualquier caso, consiga ayuda médica enseguida.

\section{Isótopos radioactivos}

Son marcadores radioactivos que se inyectan en vena, normalmente talio o tecnecio, para obtener pruebas de imagen que nos sirven para estudiar la forma y contracción del ventrículo así como la circulación coronaria, sin que presenten peligro alguno, ya que tienen una radiación débil, son de vida corta y se eliminan rápidamente del organismo.

\section{LDL Aféresis}

La LDL-aféresis es un procedimiento similar a la diálisis renal, que permite la eliminación de la sangre de las partículas de LDL (colesterol malo) en los casos de hipercolesterolemia grave. El procedimiento consiste en extraer la sangre o plasma a través de una cánula de uno de los brazos, y

\footnotetext{
352 Vol. 4, núm. 4, octubre 2018, pp. 308-360 
hacerla pasar por una columna, donde se extrae las lipoproteínas por distintos métodos. Luego, la sangre vuelve a la persona mediante una cánula localizada en el otro antebrazo. A mediados de la década de los 70, se comenzó con el intercambio de plasma en pacientes con hipercolesterolemia familiar homocigota. En el transcurso de los últimos 20 años, el desarrollo tecnológico ha evolucionado, y la aféresis de LDL ha adquirido características que permiten la eliminación mucho más específica de las LDL y de otras lipoproteínas, junto con una mayor versatilidad de su uso y con la posibilidad de iniciar el procedimiento a edades cada vez más tempranas en los niños.

\section{Lipidos ¿Qué son los Lípidos?}

El término Lípido se emplea normalmente para referirse a las grasas presentes en la sangre, como el colesterol y los triglicéridos. Cuando su cantidad es excesiva, resultan perjudiciales; sin embargo, es importante que siempre estén presentes en niveles normales, porque se encargan de realizar funciones imprescindibles en el organismo.

\section{Lipochip ¿Qué es el Biochip?}

Se trata de una superficie de cristal modificada químicamente en la que están depositadas un gran número de secuencias génicas complementarias a cada una de las mutaciones que se desea estudiar. Estas secuencias se hibridan con fragmentos de ADN, marcados con una molécula fluorescente, procedente de la muestra que se va a analizar y que reconocen específicamente al alelo normal y al mutado. Al iluminar el biochip con un láser podemos identificar a qué secuencias se ha unido la muestra problema y permite discriminar específicamente entre un paciente normal, un heterocigoto y un homocigoto. 
Lipoprotein(a) [Lp(a)]

Se trata de una partícula de LDL que lleva asociada una proteína que se encuentra en la circulación sanguínea llamada apolipoproteína (a). Elevados niveles en sangre, aumenta el riesgo de desarrollar la enfermedad cardiovascular prematura. Las personas con HF presentan frecuentemente niveles elevados de $\mathrm{Lp}(\mathrm{a})$.

Mutación (sinónimos: alteración de la secuencia; mutación del splicing)

Cualquier alteración producida en un gen con respecto a su estado natural; puede ser patológica o una variante no patológica.

Nitratos

Son los medicamentos de uso más frecuente para el tratamiento de la enfermedad coronaria. Producen vasodilatación y son capaces de mejorar la irrigación del corazón y de disminuir el trabajo que ha de realizar.

\section{Paro cardíaco}

El paro cardíaco ocurre cuando las señales eléctricas que hacen latir el corazón se descontrolan. El ritmo del corazón se vuelve caótico y el corazón no puede bombear la sangre. Algunas veces un ataque al corazón puede causar un paro cardíaco. El paro cardíaco también puede ser el resultado de un paro respiratorio, de electrocución, de ahogarse, de atragantarse o de trauma. También puede ocurrir sin causa desconocida. La muerte cerebral y la muerte clínica pueden producirse en solo 4 o 6 minutos. Las probabilidades de sobrevivir a un paro cardiaco disminuyen entre un $7 \%$ y un $10 \%$ por cada minuto que pasa sin recibir tratamiento. Pocos intentos de

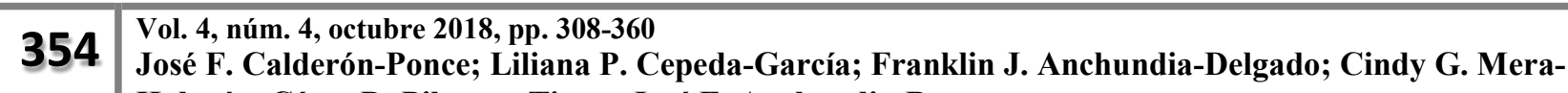
Holguín; César D. Pibaque-Tigua; José E. Anchundia-Baque
} 
resucitación tienen éxito después de haber trascurrido 10 minutos. La buena noticia es que el paro cardíaco es reversible en la mayoría de los casos, si se trata de inmediato con resucitación cardiopulmonar y con un Shock eléctrico al corazón durante 7 o 10 minutos. El shock elimina el ritmo anormal y permite restablecer el ritmo normal del corazón. Este proceso se llama desfibrilación.

Perfil lipídico

¿Qué significa perfil lipídico completo?

Es un análisis de sangre ordenado por el médico de cabecera o por el especialista, que sirve para determinar los niveles de colesterol total, colesterol LDL, colesterol HDL y triglicéridos. Sirve para establecer el diagnóstico y tratamiento de la enfermedad del paciente.

Placa de ateroma

Son placas situadas en las paredes internas de las arterias, formadas a partir del exceso de lipoproteínas LDL y triglicéridos, a los que se suma el depósito de tejido fibroso. Por su naturaleza fibrosa, provoca la disminución de la flexibilidad del vaso (arterioesclerosis=endurecimiento de las arterias), así como el estrechamiento de su luz. Puede afectar a cualquier arteria, favoreciendo la formación de trombos, al dificultar el paso de la sangre. Se trata del accidente isquémico. Cuando afecta a una arteria del cerebro, ocurre un infarto o trombosis cerebral. También puede afectar a las arterias de las extremidades inferiores.

\section{Proteómica}


Es la ciencia que correlaciona las proteinas con sus genes, y en la que convergen tres disciplinas diferentes que contribuyen por igual a la solución de problemas complejos: las metologías de separación, la espectrometría de masas y la bioinformática.

\section{Stent}

Es una malla metálica de forma tubular que se implanta en una arteria, después de hacer una angioplastia. Actúa como un soporte o armazón para mantener abierto el vaso sanguíneo. En el caso de la cardiopatía isquémica, el stent, al mantener abierto el vaso, contribuye a mejorar el flujo de sangre al músculo cardíaco y a reducir el dolor de la angina de pecho.

\section{Xantelasmas}

Se trata de un bulto plano, depósito de colesterol de color amarillento-anaranjado, situado en los párpados o debajo del ojo indicándonos un posible problema lipídico.

\section{Xantomas}

Los xantomas tendinosos se presentan como engrosamientos, tumefacciones o irregularidades de los tendones, y los más frecuentes ocurren en el tendón de Aquiles y en los tendones del dorso de las manos.

\section{Conclusiones.}

En conclusión, los resultados del presente estudio demuestran que el grado de consecución de los objetivos terapéuticos del colesterol LDL ha mejorado, particularmente en los pacientes en prevención secundaria o con diabetes, a expensas de una mayor utilización de estrategias farmacológicas de moderada/alta potencia. Por tanto, este estudio avala la utilidad y la eficacia del

\footnotetext{
356 Vol. 4, núm. 4, octubre 2018, pp. 308-360 
seguimiento activo en Atención Primaria en el control de los pacientes de alto riesgo vascular como herramienta del proceso asistencial en \% de reducción necesario para conseguir el OT (c-LDL $<100$ $\mathrm{mg} / \mathrm{dL})-22,9-22,7-24,424,619,4$ 16,1 14,5 -30,0 -20,0 - 10,0 0,0 10,0 20,0 30,0 VB V2 V3 VF Media del \% de reducción necesario para alcanzar OT en los que NO lo han conseguido Media del $\%$ de exceso de reducción en los que SÍ han conseguido OT Fig. 4.- Reducción necesaria para conseguir objetivo terapéutico. 051_8998 Intervencion activa.indd 2732 01/05/15 02:14 Intervención activa en la hipercolesterolemia Nutr Hosp. 2015; 31(6):2727-2734 2733 de pacientes con riesgo cardiovascular alto de Atención Primaria; estudio ESPROCOL nuestro entorno. Sin embargo, también pone de manifiesto la necesidad de un control más eficaz de los pacientes dislipidémicos.

Por lo que respecta a la estrategia farmacológica hipolipemiante, en la última visita hubo un claro predominio de la estrategia de moderada-alta potencia. En concreto, casi se dobló la prescripción de estatinas potentes a dosis elevadas (atorvastatina $80 \mathrm{mg}$ ), así como el tratamiento de coadministración de estatina más ezetimiba.

Globalmente, el $65 \%$ de los pacientes alcanzaron los objetivos terapéuticos en colesterol LDL. Estos resultados muestran una discreta mejoría con respecto a los referidos en el Informe SEA 200727, y superponibles a los referidos para los pacientes españoles incluidos en el estudio L-TAP 2, pero netamente inferior a otros como los Países Bajos, Estados Unidos, Canadá y Corea28. Esta situación de déficit terapéutico tiene gran relevancia clínica, ya que la falta de consecución de los objetivos de colesterol LDL se asocia a una elevada morbimortalidad cardiovascular, la cual se reduce tanto más cuanto menor es la concentración de colesterol LDL alcanzada.

\footnotetext{
357 Vol. 4, núm. 4, octubre 2018, pp. 308-360 José F. Calderón-Ponce; Liliana P. Cepeda-García; Franklin J. Anchundia-Delgado; Cindy G. MeraHolguín; César D. Pibaque-Tigua; José E. Anchundia-Baque
} 
El diagnóstico de colesterol alto (hipercolesterolemia) requiere únicamente de la realización de una análisis de sangre en ayunas y otros para descartar un hipotiroidismo o alguna enfermedad pueda ser responsable de la elevación del colesterol. En todos se debe investigar la presencia de otros factores de riesgo cardiovascular como tabaquismo, hipertensión arterial, diabetes, cantidad de colesterol-HDL (bueno) en sangre, para estimar así cual es el riesgo del paciente para desarrollar en el futuro una complicación cardiovascular.

\section{Bibliografía.}

1. Martínez MV, Llácer A. Mortalidad en España en 1997. Bol Epidemiol Sem 2000;8:253-60. [ $\underline{\text { Links }}$ ]

2. Martínez MV, Llácer A. Mortalidad en España en 1996. Bol Epidemiol Sem 1999;7:169-6. [ $\underline{\text { Links }}$ ]

3. Martínez MV, Llácer A. Mortalidad en España en 1995. Bol Epidemiol Sem 1998;6:105-11. [ Links ]

4. Villar F, Banegas JR, Rodríguez F, Rey J. Mortalidad cardiovascular en España y sus comunidades autónomas (1975-1992). Med Clin (Barc) 1998;110:321-7. [ Links ]

5. Medrano MJ, Almazán J, Sierra MJ, Olalla MT. Situación epidemiológica de las enfermedades cardiovasculares arterioscleróticas (I): mortalidad y morbilidad. Bol Epidemiol Sem 1998;6:149-53. [ Links ]

6. Villar F, Banegas JR. La mortalidad cardiovascular en España. Rev San Hig Pub 1991;65:57. [ Links ]

7. Sans S, Kesteloot H, Kromhout D. The burden of cardiovascular disease mortality in Europe. Task Force on the European Society of Cardiology on Cardiovascular Mortality and Morbidity Statistics in Europe. Eur Heart J 1997;18:1231-48. [ Links ]

8. Plaza I, Villar F, Mata P, Pérez F, Maiquez A, Casasnovas JA, et al. Control de la colesterolemia en España, 2000. Un instrumento para la prevención cardiovascular. Rev Esp Cardiol 2000;53:815-37. [ Links ]

9. Álvarez A. Las tablas de riesgo cardiovascular. Una revisión crítica. MEDIFAM 2001;11:122-39. [ [ Links ]

10. Bonné MV, González O, Charques E, Alonso MM. Riesgo coronario y prescripción en pacientes con hipercolesterolemia en atención primaria. Aten Primaria 2000;25:209-13. [ L Links ] 
11. Wallis EJ, Ramsay LE, Haq IU, Ghahramani P, Jackson PR, Rowland-Yeo K, et al. Coronary and cardiovascular risk estimation for primary prevention: validation of a new Sheffield table in the 1995 Scottish health survey population. BMJ 2000; 320:671-6. [ Links ]

12. Wilson PWF, D'Agostino RB, Levy D, Belanger AM, Silbershatz H, Kannel WB. Prediction of coronary heart disease using risk factor categories. Circulation 1998;97:1837-47. [ Links ]

13. Grundy SM, Pasternak R, Greenland P, Smith S, Fuster V. Assessment of cardiovascular risk by use of multiple-risk-factor assessment equations. Circulation 1999;100:1481-92. [ Links ]

14. Velasco JA, Cosín J, Maroto JM, Muñiz J, Casasnovas JA, Plaza I, et al. Guías de práctica clínica de la Sociedad Española de Cardiología en prevención cardiovascular y rehabilitación cardíaca. Rev Esp Cardiol 2000;53:1095-120. [ Links ]

15. Haq IU, Ramsay LE, Jackson PR, Wallis EJ. Prediction of coronary risk for primary prevention of coronary heart disease: a comparison of methods. QJM 1999;92:379-85. [ Links ]

16. Jones AF, Walker J, Jewkes C, Game FL, Bartlett WA, Marshall T, et al. Comparative accurary of cardiovascular risk prediction methods in primary care patients. Heart 2001;85: 3743. [ Links ]

17. Grupo de Prevención Cardiovascular del Programa de Actividades Preventivas y Promoción de la Salud (PAPPS) de la Sociedad Española de Medicina de Familia y Comunitaria (semFYC). Guía de prevención cardiovascular. Madrid: Sersa, 1996. [ Links ]

18. Ramachandran S, Labib MH. Hyperlipidaemia and primary prevention of coronary heart disease: are the right patients being treated? J Cardiovasc Risk 2000;7:245-9. [ Links ]

19. Bonet $\mathrm{S}$, García I, Tomás $\mathrm{P}$, Tapia I, Gussinyé P, Mundet X. ¿Cuándo y cómo tratamos a nuestros pacientes hipercolesterolémicos? Aten Primaria 1999;24:397-403. [ Links ]

20. Sanz T, Escortell E, Fernández MI, López C, Medina B, Torres C, et al. Calidad del tratamiento farmacológico en pacientes con hiperlipemia de 4 áreas de salud. Aten Primaria 2000;26:368-73. [ Links ]

21. Wierzbicki AS, Reynolds TM, Gill K, Alg S, Crook MA. A comparison of algorithms for initiation of lipid lowering therapy in primary prevention of coronary heart disease. J Cardiovasc Risk 2000;7:63-71. [ [ Links ]

22. Durrington PN, Prais H, Bhatnagar D, France M, Crowley V, Khan J, et al. Indications for cholesterol-lowering medication: comparison of risk-assessment methods. Lancet 1999;353: 278-81. [ Links ]

23. Isles CG, Ritchie LD, Murchie P, Norrie J. Risk assessment in primary prevention of coronary heart disease: randomised comparison of three scoring methods. BMJ 2000;320:690-1. [ Links ] 
24. De Velasco JA, Cosín J, López JL, De Teresa E, De Oya M, Carrasco JL, et al. La prevención secundaria del infarto de miocardio en España. Estudio PREVESE. Rev Esp Cardiol 1997;50: 406-15. [ Links ]

25. Insalud (Atención Primaria Baleares). Criterios de utilización de estatinas. Bol Inf Terap $2000 ; 2: 61-8$. [ Links ] 